Milagros Maravi $\left.i^{*}\right)$

\title{
Mecanismos de simplificación administrativa a la luz de las recientes modificaciones a la Ley del Procedimiento Administrativo General, Ley 27444, y la reciente Ley de Prevención y Eliminación de Barreras Burocráticas, Decreto Legislativo 1256(")
}

Mechanisms for administrative simplification in light of recent amendments to the General Administrative Procedure Law, 27444, and the recent Law of Prevention and Elimination of Bureaucratic Barriers, Legislative Decree 1256

\section{LA LPAG MODIFICADA POR EL DECRETO LEGISLATIVO 1272, Y LA LEY DE ELIMINACIÓN DE BARRERAS BUROCRÁTICAS HAN RECOGIDO LAS RECOMENDACIONES DE LA OCDE EN TEMAS DE SIMPLIFICACIÓN ADMINISTRATIVA. DE ESTA MANERA, SE HA IMPLEMENTADO EN EL ORDENAMIENTO PERUANO, EL PROCEDIMIENTO ADMINISTRATIVO ELECTRÓNICO, LOS PROCEDIMIENTOS ADMINISTRATIVOS ESTANDARIZADOS, LA REGLA DE LA VIGENCIA INDETERMINADA DE LOS TÍTULOS HABILITANTES, LA OBLIGACIÓN DE INTEROPERABILIDAD ENTRE LAS ENTIDADES, ENTRE OTROS.}

Resumen: En el presente artículo, la autora analiza los mecanismos de simplificación administrativa implementados en la Ley del Procedimiento Administrativo General, Ley 27444, modificada por el Decreto Legislativo 1272, y en la reciente Ley de Prevención y Eliminación de Barreras Burocráticas, Decreto Legislativo 1256. Así, se podrá evidenciar que ambas normas han tomado en consideración las recomendaciones de la Organización para la Cooperación y el Desarrollo Económicos (OCDE) para (i) alivianar las cargas impuestas a los administrados en el desarrollo de los

(*) Abogada por la Pontificia Universidad Católica del Perú. Máster, en Administración Pública por el Instituto Ortega y Gasset, adscrito a la Universidad Complutense de Madrid. Socia de Rubio, Leguía, Normand. Correo electrónico: mmaravi@rubio.pe

$\left.{ }^{* *}\right) \quad$ Nota del Editor: este artículo fue recibido el 31 de mayo de 2017 y su publicación fue aprobada el 28 de junio del mismo año. 
Mecanismos de simplificación administrativa a la luz de las recientes modificaciones a la Ley del Procedimiento Administrativo General, Ley 27444, y la reciente Ley de Prevención y Eliminación de Barreras Burocráticas, Decreto Legislativo 1256

Mechanisms for administrative simplification in light of recent amendments to the General Administrative Procedure Law, 27444, and the recent Law of Prevention and Elimination of Bureaucratic Barriers, Legislative Decree 1256

procedimientos administrativos, (ii) empoderar a la Presidencia del Consejo de Ministros para que implemente medidas adicionales de simplificación administrativa y supervise el cumplimiento por parte de las entidades, y (iii) eliminar las barreras burocráticas en nuestro ordenamiento.

Palabras clave: Simplificación Administrativa - Ley 27444 - Decreto Legislativo 1272 - Decreto Legislativo 1256 Procedimiento Administrativo - Barreras Burocráticas

\begin{abstract}
In this academic article, the author analyzes the administrative simplification mechanisms implemented in the Law of General Administrative Procedure, 27444, as amended by Legislative Decree 1272, and in the recent Law of Prevention and Elimination of Bureaucratic Barriers, Legislative Decree 1256. Thus, it can be seen that both laws have taken into account the recommendations of the Organisation for Economic Co-operation and Development (OECD) in order to (i) alleviate the burdens imposed on the citizens in the development of administrative procedures, (ii) empower the Office of the President of the Council of Ministers in order to implement administrative simplification measures and to monitor compliance by entities, and (iii) eliminate bureaucratic barriers in our legal framework.
\end{abstract}

Keywords: Administrative Simplification - Law 27444 - Legislative Decree 1272 - Legislative Decree 1256 - Administrative Procedure - Bureaucratic Barriers

\section{Introducción}

Nuestro país ha avanzado en simplificación administrativa. Así lo demuestran las diversas normas, junto a sus modificaciones, que han sido emitidas en los últimos años ${ }^{(1)}$.

Asimismo, con la finalidad de perfeccionar la normativa de simplificación administrativa y así cumplir con las recomendaciones de la Organización para la Cooperación y el Desarrollo Económicos (En adelante, la "OCDE"), el Congreso de la República permitió al Poder Ejecutivo, por medio del literal h) de la Ley que delega en el Poder Ejecutivo la facultad de legislar en materia de reactivación económica y formalización, seguridad ciudadana, lucha contra la corrupción, agua y saneamiento y reorganización de Petroperú S.A., Ley 30506 , modificar el marco normativo del procedimiento administrativo general con el objetivo de simplificar, optimizar y eliminar procedimientos administrativos, priorizar y fortalecer las acciones de fiscalización posterior sanción, incluyendo la capacidad operativa para llevarlas a cabo; dictar normas generales y específicas para la estandarización de procedimientos administrativos comunes en la administración pública con la finalidad de hacer predecibles sus requisitos y plazos; y aprobar medidas que permitan la eliminación de barreras burocráticas en los tres (3) niveles de gobierno.

De esta manera, si bien por medio de la delegación de facultades legislativas el Poder Ejecutivo modificó diversas normas en aras de simplificar específicos procedimientos administrativos $^{(2)}$, la finalidad del presente artículo es comentar sobre dos (2) normas que son importantes para el desarrollo y consolidación de la simplificación administrativa en nuestro ordenamiento. Se trata de la Ley del Procedimiento Administrativo General,

(1) Entre ellas, se encuentran el Decreto Legislativo que crea el Sistema Único de Trámites (SUT) para la simplificación de procedimientos administrativos y servicios prestados en exclusividad, 1203; el Decreto Legislativo que refuerza las facultades sobre eliminación de barreras burocráticas para el fomento de la competitividad, 1212; la Resolución Ministerial que aprueba TUPA Modelo de los procedimientos administrativos de licencia de funcionamiento e inspecciones técnicas de seguridad en edificaciones para las Municipalidades Provinciales y Distritales, 088-2015-PCM; la Resolución de Secretaría de Gestión Pública que aprueba el Manual del Centro de Mejor Atención al Ciudadano - Centro MAC, 004-2012-PCM-SGP.

(2) Decreto Legislativo que modifica la Ley 28976, Ley Marco de Licencia de Funcionamiento, 1271; Decreto Legislativo que modifica la Ley 29090, Ley de Regulación de Habilitaciones Urbanas y Edificaciones, 1287; Decreto Legislativo que aprueba diversas medidas de simplificación administrativa, 1246; Decreto Legislativo que aprueba medidas adicionales de simplificación administrativa, 1310. 
Milagros Maraví

Ley 27444 (En adelante, la "LPAG"), la cual fue modificada por medio del Decreto Legislativo 1272, y la reciente Ley de Prevención y Eliminación de Barreras Burocráticas (En adelante, la "Ley de Eliminación de Barreras Burocráticas"), aprobada por el Decreto Legislativo 1256.

Consideramos que ambas normas permiten que la ciudadanía pueda percibir con sustento en la realidad que en nuestro país el "Estado existe para beneficio de las personas, el ser humano no existe para beneficio del Estado" (Siegan 1993, 5).

\section{Decreto Legislativo que modifica la Ley 27444, Ley del Procedimiento Administrativo General y deroga la Ley 29060, Ley del Silencio Administrativo, 1272}

La LPAG tiene como finalidad ser la norma unificadora de la regulación de los procedimientos administrativos, de manera que era necesario modificarla para generalizar su aplicación como estándar mínimo, perfeccionarla y establecer medidas adicionales que coadyuven a la simplificación administrativa. Así, la delegación de facultades permitió al Poder Ejecutivo modificar la LPAG con el objetivo de simplificar, optimizar y eliminar procedimientos administrativos, priorizar y fortalecer las acciones de fiscalización posterior sanción, incluyendo la capacidad operativa para llevarlas a cabo; y dictar normas generales y específicas para la estandarización de procedimientos administrativos comunes en la administración pública con la finalidad de hacer predecibles sus requisitos y plazos.

En razón a lo anterior, se emitió el Decreto Legislativo que modifica la Ley 27444, Ley del Procedimiento Administrativo General y deroga la Ley 29060, Ley del Silencio Administrativo, 1272. Si bien esta norma contiene interesantes novedades, sería imposible comentarlas todas en el presente artículo; por ello, nos enfocaremos en las novedades de la regulación del procedimiento administrativo general, incluyendo la reincorporación del silencio administrativo; y el empoderamiento de la Presidencia del Consejo de Ministros (En adelante, la "PCM").

\subsection{Modificaciones a la regulación del procedimiento administrativo general}

2.1.1 Contenido de la Ley del Procedimiento Administrativo General

La LPAG tiene como finalidad establecer la regulación general aplicable a todos los procedimientos administrativos que son desarrollados por las diferentes entidades de la Administración Pública. Para salvaguardar este objetivo, se ha precisado, en el numeral 1 del artículo II del Título Preliminar de la LPAG, que (i) contiene normas comunes para las actuaciones de la función administrativa del Estado, y (ii) regula todos los procedimientos administrativos desarrollados en las entidades, incluyendo los procedimientos especiales. De este modo, los procedimientos especiales deberán respetar la regulación general prevista en la LPAG a efectos de estructurar y desarrollar todos los procedimientos administrativos.

Vinculado con lo anterior, se ha considerado necesario disponer, en el numeral 2 del mismo artículo, que las leyes que crean y regulan los procedimientos especiales no podrán imponer condiciones menos favorables a los administrados que las previstas en la presente LPAG. Esta norma establece los derechos mínimos y las garantías mínimas que debe tener todo administrado en el desarrollo de los procedimientos administrativos, de manera que ninguna otra ley o norma inferior puedan desconocer dichos derechos y garantías.

\subsubsection{Instauración del procedimiento administrativo electrónico \\ La reciente modificación a la LPAG tiene como novedad la instauración del procedimiento administrativo electrónico. Si bien diversas entidades ya habían implementado sus procedimientos administrativos utilizando medios electrónicos ${ }^{(3)}$, era necesario que la LPAG estableciera un marco general sobre el procedimiento administrativo electrónico, a}

(3) Por ejemplo, la Dirección General de Medicamentos, Insumos y Drogas (DIGEMID), la Dirección General de Salud Ambiental (DIGESA), el Servicio Nacional de Sanidad Agraria del Perú (SENASA), entre otros, utilizan la Ventanilla Única del Comercio Exterior (VUCE). 
Mecanismos de simplificación administrativa a la luz de las recientes modificaciones a la Ley del Procedimiento Administrativo General, Ley 27444, y la reciente Ley de Prevención y Eliminación de Barreras Burocráticas, Decreto Legislativo 1256

Mechanisms for administrative simplification in light of recent amendments to the General Administrative Procedure Law, 27444, and the recent Law of Prevention and Elimination of Bureaucratic Barriers, Legislative Decree 1256

fin de que todas las entidades de la Administración Pública respeten los derechos y garantías mínimas a favor del administrado.

Al respecto, se debe tener en consideración que la OCDE ha destacado la importancia del uso de las Tecnologías de la Información y Comunicación (En adelante "TIC") a fin de implementar la simplificación administrativa en los ordenamientos (OCDE 2009, 8-9). En la misma línea, la doctrina ha señalado que el uso de las Tecnologías de la Información y Comunicación tiene como objetivos facilitar y simplificar a los ciudadanos la realización de cuantas actuaciones tengan que desarrollar ante la Administración Pública; y agilizar la tramitación de los procedimientos administrativos gracias al empleo de la tecnología como factor decisivo en el aumento de la eficacia y la eficiencia en la gestión de la Administración Pública (Martínez 2010, 95).

En ese sentido, teniendo en cuenta que nuestro país se encuentra en camino a poder pertenecer a la OCDE, la nueva incorporación del artículo 29-A en la LPAG establece que el procedimiento administrativo podrá realizarse total o parcialmente a través de tecnologías y medios electrónicos, sin perjuicio del uso de medios físicos tradicionales.

Para ello, el procedimiento administrativo electrónico debe contar en un expediente, el cual debe contener los documentos presentados por los administrados, terceros y otras entidades, así como toda la documentación remitida al administrado.

Además, la LPAG acierta en disponer que el procedimiento administrativo electrónico tiene los mismos efectos legales que el procedimiento administrativo tradicional, toda vez que no existe ninguna diferencia de validez entre ambos. En ese sentido, se establece que el procedimiento administrativo electrónico deberá respetar todos los principios, derechos y garantías del debido procedimiento previstos, sin que se afecte el derecho de defensa ni la igualdad de las partes, debiendo prever las medidas pertinentes cuando el administrado no tenga acceso a medios electrónicos.
Igualmente, se señala que los actos administrativos que se emitan tienen la misma validez y eficacia jurídica que los actos realizados por medios físicos tradicionales, así como las firmas digitales y documentos generados y procesados a través de tecnologías y medios electrónicos tendrán la misma validez legal que los documentos manuscritos.

De este modo, la nueva normativa permite que no exista impedimento alguno a efectos de que la Administración Pública pueda utilizar medios electrónicos en los procedimientos administrativos de su competencia. Así, el administrado puede percibir que se libera de la carga de tener que apersonase a la entidad correspondiente y hacer colas.

2.1.3 Calificación de los procedimientos administrativos: aprobación automática y evaluación previa

La clasificación de los procedimientos administrativos son (i) aprobación automática o (ii) evaluación previa, en cuyo caso se subdivide en sujeto a silencio administrativo positivo o silencio administrativo negativo. De esta manera, no existe ninguna otra calificación posible del procedimiento administrativo en nuestro ordenamiento.

Sin embargo, la realidad nos evidenció lo contrario. Diversos Textos Únicos de Procedimientos Administrativos (En adelante, "TUPA") establecían que ciertos procedimientos administrativos no se encontraban sujetos a ninguna calificación ${ }^{(4)}$, de manera que el administrado estaba sujeto a que la Administración Pública resuelva la solicitud en el plazo y en la forma en que ésta disponga.

(4) Por ejemplo, el TUPA de la Municipalidad de Villa María del Triunfo, aprobado por Decreto de Alcaldía 003-2016/MVT, no señala la calificación, ni el plazo de resolución de los siguientes procedimientos administrativos: (i) autorización para la instalación y conexiones domiciliarias de agua y desagüe, (ii) constancia de posesión de predio, y (iii) recepción de obras finales de habilitación urbana. 
Milagros Maraví

Por ello, se ha modificado el artículo 30 de la LPAG a fin de precisar que todos los procedimientos administrativos son de (i) aprobación automática o (ii) evaluación previa. Así, no hay menor duda de que las entidades se encuentran obligadas legalmente a calificar sus procedimientos administrativos de esa manera, sin que puedan crear otro tipo de calificación. De otro modo, el funcionario responsable estaría incurriendo en responsabilidad administrativa en aplicación del numeral 22 del artículo 239 de la LPAG.

2.1.4 Régimen del procedimiento de aprobación automática En aras de incorporar medidas de simplificación administrativa, se ha considerado conveniente que el artículo 31 de la LPAG amplíe el ámbito de aplicación de la aprobación automática en los procedimientos administrativos. En razón a ello, se han incorporado dos (2) nuevos supuestos, los cuales son (i) habilitar el ejercicio de derechos preexistentes del administrado y (ii) obtener la inscripción de registros administrativos.

En el primer supuesto, estamos ante aquellas solicitudes en los que el administrado solicita a la Administración Pública la obtención de licencias y autorizaciones, puesto que, en estos casos, el administrado cuenta con un derecho preexistente para ejercer una determinada actividad, pero debe cumplir con ciertos requisitos establecidos en la normativa a fin de poder obtener el título habilitante correspondiente y, de esta manera, hacer ejercicio de dicho derecho.

En el segundo supuesto, estamos ante aquellos procedimientos administrativos en los que el administrado solicita la inscripción de este o de algún bien del cual es titular, en algún registro administrativo. De esta forma se libera la carga al administrado de sobrellevar un largo procedimiento administrativo a fin de obtener y ejercer un derecho de manera rápida.

\subsubsection{Reincorporación de la regulación del silencio} administrativo

Entre las principales novedades, se encuentra la reincorporación de la regulación del silencio administrativo de la Ley del Silencio Administrativo, 29060 (En adelante, la "LSA") a la LPAG, toda vez que no existía fundamento para que se encontrara en una norma diferente a esta. En el texto original de la LPAG, el legislador consideró conveniente que la regulación del silencio administrativo se encontrará en esta norma. Ello era acertado debido a que la LPAG tiene como finalidad ser la norma unificadora de las disposiciones que regulan el procedimiento administrativo general, las cuales comprenden, sin menor duda, la aplicación del silencio administrativo. No obstante, posteriormente, se publicó la LSA, la cual derogó las disposiciones del silencio administrativo en la LPAG y ha tenido diversas críticas, debido a que, si bien tenía como sustento ser una medida de simplificación administrativa, tuvo efectos contrarios en la práctica.

Así, si lo correcto era, por técnica legislativa, devolver el tratamiento del silencio administrativo a la LPAG; mantener algunas disposiciones de la LSA, pero en el contexto de la LPAG; derogar la LSA; y aclarar en la LPAG los supuestos de silencio administrativo positivo y negativo (Maraví 2011, 111-2). En ese sentido, con la finalidad de perfeccionar la regulación del silencio administrativo, no solo se ha reincorporado a la LPAG sino que se han incrementado los supuestos de aplicación del silencio administrativo positivo y han restringido los supuestos sujetos al silencio administrativo negativo.

Lo anterior se evidencia en la reincorporación de la regla de que los procedimientos administrativos están sujetos al silencio administrativo positivo por medio del inciso 1 del numeral 33.1 del artículo 33 de la LPAG, el cual señala que todos los procedimientos a instancia de parte no sujetos al silencio administrativo negativo taxativo, están sujetos a silencio administrativo positivo. De esta manera, se elimina el mensaje que parecía dar la LSA, con respecto a que la regla era el silencio administrativo negativo, toda vez que había incrementado los supuestos de aplicación de este silencio en vez de restringirlo en aras de la simplificación administrativa.

Dicha regulación necesitaba ser complementada con la restricción de los 
Mecanismos de simplificación administrativa a la luz de las recientes modificaciones a la Ley del Procedimiento Administrativo General, Ley 27444, y la reciente Ley de Prevención y Eliminación de Barreras Burocráticas, Decreto Legislativo 1256

Mechanisms for administrative simplification in light of recent amendments to the General Administrative Procedure Law, 27444, and the recent Law of Prevention and Elimination of Bureaucratic Barriers, Legislative Decree 1256

supuestos de aplicación del silencio administrativo negativo, dado que, de otro modo, no se podrían evidenciar los beneficios a favor del administrado. Por ello, el artículo 34 de la LPAG establece que este silencio es aplicable únicamente en aquellos casos en los que la petición del administrado puede afectar significativamente el interés público e incida en la salud, el medio ambiente, los recursos naturales, la seguridad ciudadana, el sistema financiero y de seguros, el mercado de valores, la defensa comercial, la defensa nacional y el patrimonio cultural de la nación, así como en aquellos procedimientos de promoción de inversión privada, procedimientos trilaterales y en los que generen obligación de dar o hacer del Estado y autorizaciones para operar casinos de juego y máquinas tragamonedas. Asimismo, es de aplicación para aquellos procedimientos por los cuales se transfiera facultades de la administración pública, y en aquellos procedimientos de inscripción registral.

Como se puede evidenciar, el ordenamiento requiere que exista una potencial afectación significativa a determinados bienes jurídicos a fin de que el procedimiento administrativo sujeto a silencio administrativo negativo se encuentre justificado. Al respecto, la práctica demostró que las entidades habían interpretado que bastaba una posible afectación, sin importar su intensidad, para que el procedimiento administrativo esté sujeto al silencio administrativo negativo. Con la finalidad de contrarrestar lo anterior, la normativa vigente requiere que las entidades sustenten técnicamente la posible afectación significativa a efectos de que el procedimiento administrativo esté calificado como de silencio administrativo negativo. Con esta nueva obligación, se busca frenar la arbitrariedad de las entidades al momento de calificar sus procedimientos administrativos.

Por otro lado, era necesario que la LPAG regule sobre el medio probatorio de la aprobación de la petición realizada por aplicación del silencio administrativo positivo. En ese sentido, se recoge de la derogada LSA que como constancia de la aplicación del silencio administrativo positivo de la solicitud del administrado, bastará la copia del escrito o del formato presentado conteniendo el sello oficial de recepción, sin observaciones e indicando el número de registro de la solicitud, fecha, hora y firma del agente receptor. También se realiza la precisión de que, en el caso de procedimientos administrativos electrónicos, basta el correo electrónico que deja constancia del envío de la solicitud.
Adicionalmente, si el administrado quiere manejarse con mayores garantías, puede presentar una declaración jurada ante la entidad que permitió la aplicación del silencio administrativo positivo para hacer valer sus derechos. De esta forma, el cargo de recepción será prueba suficiente de la resolución aprobatoria ficta de la solicitud o trámite iniciado.

Teniendo en cuenta lo anterior, se ha modificado el numeral 188.2 del artículo 188 de la LPAG, con la finalidad de precisar que el silencio positivo tiene para todos los efectos el carácter de resolución que pone fin al procedimiento, sin perjuicio de la potestad de nulidad de oficio. La versión anterior de este numeral no hacía distinción entre el silencio administrativo positivo y el silencio administrativo negativo, lo cual era jurídicamente incorrecto, dado que únicamente el silencio administrativo positivo pone fin al procedimiento administrativo, mientras que el silencio administrativo negativo es una garantía procedimental del administrado para poder recurrir a la siguiente instancia a fin de cuestionar la negativa de la Administración Pública (Huapaya 2013, 333).

2.1.6 Precisiones sobre la legalidad del procedimiento

El artículo 36 de la LPAG regula la legalidad del procedimiento, la cual tiene por finalidad establecer cuáles son las normas por medio de las cuales las entidades se encuentran autorizadas para crear procedimientos administrativos, sus requisitos y costos. Así, en este artículo se reconoce que los organismos reguladores pueden establecer procedimientos y requisitos en ejercicio de su función normativa, la cual se encuentra reconocida en el numeral 3 del artículo 32 de la Ley Orgánica del Poder Ejecutivo, Ley $29158^{(5)}$, y el literal c) del numeral 3.1 del artículo 3 de la Ley Marco de los Organismos 
Milagros Maraví

Reguladores de la Inversión Privada en los Servicios Públicos, Ley $27332^{(6)}$.

Igualmente, se ha dispuesto la prohibición de que, en los TUPA, no se pueda crear procedimientos y nuevos requisitos, salvo en lo relativo a la determinación de las tasas que sean aplicables. Era importante esta precisión, debido a que los TUPA no constituyen ninguna norma en nuestro ordenamiento; únicamente compila, en un solo texto, los diferentes procedimientos administrativos junto a sus requisitos. Lamentablemente, existen entidades que no entendieron la normativa de la LPAG en ese sentido, ya que parecería que asumieron que el dispositivo de aprobación del TUPA era suficiente a fin de crear procedimientos y requisitos. Lo anterior se ha podido evidenciar en diversas resoluciones del Instituto Nacional de Defensa de la Competencia y de la Protección de la Propiedad Intelectual (En adelante, "INDECOPI") contra las barreras burocráticas ${ }^{(7)}$.

Teniendo en cuenta lo anterior, previamente a la incorporación de un procedimiento al TUPA, debe existir una norma que apruebe su existencia, así como sus requisitos. En caso contrario, los procedimientos o los requisitos carentes de base normativa serían ilegales y, por lo tanto, inexigibles al administrado. En caso de incumplimiento, el numeral 17 del artículo 239 de la LPAG establece que las autoridades o el personal al servicio de las entidades incurrirán en responsabilidad administrativa.

Por otro lado, una novedad importante es la regulación de la legalidad de los procedimientos administrativos a cargo de las personas jurídicas que presenten servicios públicos o ejercen alguna función administrativa. Así, estas tienen la obligación de publicitar los procedimientos administrativos, incluyendo sus requisitos. Como se puede evidenciar, Ia LPAG establece una clara diferencia entre la publicidad de los procedimientos administrativos de las entidades y las personas jurídicas, puesto que, en el primer supuesto, las entidades se encuentran en la obligación de publicitar sus procedimientos a través del TUPA (los cuales son elaborados por medio del Sistema Único de Trámites $\left.{ }^{(8)}\right)$, mientras que las personas jurídicas únicamente tienen la obligación de publicitar sus procedimientos sin estar obligados a un medio en específico. Sin perjuicio de ello, es claro que las personas jurídicas deben utilizar medios idóneos a efectos de entregar información relevante, suficiente y previa a los administrados.

2.1.7 Regulación de los Textos Único Ordenado de Procedimientos Administrativos

Tema vinculado con la legalidad del procedimiento es la regulación de los TUPA, la cual necesitaba precisiones a fin de tutelar los derechos de los administrativos para que no se les requiera procedimientos o requisitos que no estén previstos en el ordenamiento. Así, en el artículo 37 de la LPAG, se ha incorporado la precisión de que el TUPA debe contener una descripción clara y taxativa de los requisitos exigidos para la tramitación de

(5) Artículo 32. Organismos Reguladores

Los Organismos Reguladores: (...)

3. Dentro de sus respectivos ámbitos de competencia, tienen funciones supervisoras, reguladoras, normativas, fiscalizadoras y sancionadoras; y de solución de controversias y reclamos, en los términos previstos por la Ley de la materia.

(6) Artículo 3. Funciones

3.1 Dentro de sus respectivos ámbitos de competencia, los Organismos Reguladores ejercen las siguientes funciones: (...) c) Función Normativa: comprende la facultad de dictar en el ámbito y en materia de sus respectivas competencias, los reglamentos, normas que regulen los procedimientos a su cargo, otras de carácter general y mandatos u otras normas de carácter particular referidas a intereses, obligaciones o derechos de las entidades o actividades supervisadas o de sus usuarios; $(\ldots)$

(7) Por ejemplo, el INDECOPI ha declarado barreras burocráticas ilegales en las Resoluciones No. 000006-2015/SC1, 0000102015/SC1, 000016-2015/SC1, 000024-2015/SC1, 000243-2015/SC1.

(8) Dicha obligación fue dispuesta por medio del 1 del Decreto Legislativo que crea el Sistema Único de Trámites (SUT) para la simplificación de procedimientos administrativos y servicios prestados en exclusividad, 1203. 
Mecanismos de simplificación administrativa a la luz de las recientes modificaciones a la Ley del Procedimiento Administrativo General, Ley 27444, y la reciente Ley de Prevención y Eliminación de Barreras Burocráticas, Decreto Legislativo 1256

Mechanisms for administrative simplification in light of recent amendments to the General Administrative Procedure Law, 27444, and the recent Law of Prevention and Elimination of Bureaucratic Barriers, Legislative Decree 1256

cada procedimiento, los cuales deben ser aprobados por la norma correspondiente. Además, se ha eliminado la referencia a que los montos de derecho de trámite se expresarán en Unidades Impositivitas Tributarias (en adelante, "UIT"), toda vez esta nomenclatura creaba una carga adicional en el administrado al tener que calcular el monto del derecho de tramitación según la UIT vigente. Así, ahora únicamente se dispone que el monto de los derechos de tramitación se expresa en moneda de curso legal.

Por otra parte, la LPAG acierta en disponer que los servicios que no sean prestados en exclusividad por la Administración Pública deben respetar el artículo 60 de la Constitución Política del Perú(9) y las normas sobre represión de la competencia desleal. Dicho artículo reconoce el pluralismo económico y la subsidiariedad de la actividad empresarial del Estado, de manera que, debido a que nos encontramos dentro del régimen económico de Economía Social de Mercado, no es posible que el Estado, a través de sus entidades, pueda realizar actividades económicas que puedan ser desarrolladas por el sector privado. Así, el Estado podría intervenir en el mercado siempre que no exista el sector privado para satisfacer la demanda o que su actividad sea insuficiente. En la misma línea, la Administración Pública, al igual que los privados, se encuentran en la obligación de respetar las diferentes normas de represión de competencia desleal, a fin de ser concordantes con el régimen económico vigente.

Respecto a la publicidad del TUPA, se dispone que la norma que aprueba el TUPA se publica en el Diario Oficial "El Peruano", más no el texto del mismo. Esto es debido a que el texto puede ser publicitado, con menores costos y sin mayores perjuicios a la ciudadanía, en el Portal del Diario Oficial "El Peruano", el Portal de Servicios al Ciudadano y el respectivo portal institucional.

En la misma línea, se incorpora la obligación de que, para la elaboración del TUPA, las entidades evitan la duplicidad de los procedimientos administrativos en las entidades. La anterior redacción de la disposición establecía que las entidades debían procurar evitar la duplicidad de los procedimientos. Es una diferencia sutil, pero que tiene un gran efecto a favor del administrado. Así, es diferente disponer que las entidades se encuentran en la obligación de evitarla duplicidad a que intenten o se esfuercen en evitar la duplicidad de los procedimientos. De esta manera, con la normativa vigente, las entidades deberán realizar un verdadero esfuerzo a efectos de evitar dicha duplicidad que perjudica, en los hechos, a los intereses y derechos del administrado.

2.1.8 Instauración de Procedimientos Administrativos Estandarizados obligatorios Con anterioridad a la modificación de la LPAG, la PCM había emitido diferentes medidas para simplificar los procedimientos administrativos. Una de dichas medidas fue la creación de los TUPA Modelos, los cuales tenían la finalidad de uniformizar los pasos y requisitos de mismos procedimientos que son competencia de diversas entidades ${ }^{(10)}$. Lamentablemente, los TUPA Modelo no tuvieron mayor impacto en el ordenamiento, debido a que las entidades no los consideraron de obligatorio cumplimiento en el entendido de que la norma que los aprobaba era una resolución ministerial. Así, estas entidades podían alegar que su norma interna (por ejemplo, una ordenanza e inclusive un decreto supremo) prevalecía sobre la norma de aprobación del TUPA Modelo.

Por ello, con el objetivo de reforzar la función de la PCM en temas de simplificación

(9) Artículo 60. El Estado reconoce el pluralismo económico. La economía nacional se sustenta en la coexistencia de diversas formas de propiedad y de empresa.

Sólo autorizado por ley expresa, el Estado puede realizar subsidiariamente actividad empresarial, directa o indirecta, por razón de alto interés público o de manifiesta conveniencia nacional. La actividad empresarial, pública o no pública, recibe el mismo tratamiento legal.

(10) Un claro ejemplo es el TUPA Modelo de los procedimientos administrativos de Licencia de Funcionamiento e Inspecciones Técnicas de Seguridad en Edificaciones para las Municipalidades Provinciales y Distritales, aprobado por Resolución Ministerial 088-2015-PCM. 
Milagros Maraví

administrativa, el artículo 36-A de la LPAG ha otorgado competencia a esta entidad para que, mediante decreto supremo, apruebe los procedimientos administrativos estandarizados, los cuales son de obligatoria aplicación por las entidades competentes para tramitarlos. Además, se precisa que éstas se encuentran impedidas de modificarlos o alterarlos, salvo la información respecto a (i) la unidad de trámite documentario o la que haga sus veces para dar inicio al procedimiento administrativo, (ii) la autoridad competente para resolver el procedimiento administrativo, (iii) la unidad orgánica a la que pertenece y (iv) la autoridad competente que resuelve los recursos administrativos. Así, existiendo una norma con rango legal, las entidades se encuentran en la obligación de incorporar en sus TUPA los procedimientos administrativos estandarizados.

De esta manera, se mejorará la calidad, la eficiencia y la oportunidad de los procedimientos que la ciudadanía realiza ante la Administración Pública, y se eliminará los obstáculos o costos innecesarios para la sociedad, que genera el inadecuado funcionamiento de la Administración Pública y vulnera los Principios de Legalidad, Razonabilidad y Uniformidad, previstos en el artículo IV del Título Preliminar de la LPAG.

Adicionalmente, a fin de asegurar el efectivo cumplimiento, se ha dispuesto que la no actualización de los TUPA por parte de las entidades, dentro de los cinco (5) días hábiles posteriores a la entrada en vigencia de los procedimientos administrativos estandarizados, tiene como consecuencia que la autoridad incurra en responsabilidad administrativa. En la misma línea, los numerales 15 y 16 del artículo 239 de la LPAG disponen que las autoridades o el personal al servicio de las entidades también incurrirán en responsabilidad administrativa si no aplican el procedimiento estandarizado aprobado o cobran montos de derecho de tramitación superiores al establecido para los procedimientos estandarizados, respectivamente.

2.1.9 Vigencia indeterminada de los títulos habilitantes Una novedad importante es la incorporación de una nueva regla en el ordenamiento peruano respecto a la vigencia de los títulos habilitantes. En la práctica, se pudo evidenciar que los administrados se encontraban en la obligación de tener que tramitar nuevos títulos habilitantes o la renovación de los mismos por el mero paso de tiempo, pese a que las condiciones para su otorgamiento permanecieran iguales.
Además, a lo anterior se le sumaba la burocracia y la paciencia, a veces interminable, de la Administración Pública para resolver las solicitudes.

A todas luces, lo anterior tenía como consecuencia que el administrado se encuentre ante un obstáculo injustificado a fin de continuar realizando las actividades que le fueron autorizadas previamente.

Por ello, se ha incorporado la regla de que los títulos habilitantes tienen vigencia indeterminada, salvo que la ley especial señale un plazo determinado. Como se puede evidenciar, la LPAG requiere que sea una ley la cual establezca un plazo determinado de vigencia, de manera que las entidades se encuentran impedidas de poder regular un plazo por medio de una norma de rango inferior.

Sin perjuicio de lo anterior, la LPAG también ha previsto que pueden existir administrados que no requieran un nuevo título habilitante o no renueven el mismo, pese a que las condiciones para su otorgamiento hayan cambiado con el paso del tiempo. En este caso, la entidad correspondiente dejará sin efecto el título habilitante, previa fiscalización.

2.1.10 Obligación de permitir acceso a información para consulta por parte de las entidades

Se ha podido evidenciar que las entidades requieren a los administrados, en los procedimientos administrativos, diferentes requisitos que son otorgados por otras entidades. Así, el administrado se veía en la obligación de tener que iniciar, previamente al procedimiento administrativo de su interés, otros procedimientos administrados ante diferentes entidades a fin de obtener el requisito solicitado. No obstante, se debe tener en consideración que las entidades no son ajenas entre sí, dado que todas pertenecen 
Mecanismos de simplificación administrativa a la luz de las recientes modificaciones a la Ley del Procedimiento Administrativo General, Ley 27444, y la reciente Ley de Prevención y Eliminación de Barreras Burocráticas, Decreto Legislativo 1256

Mechanisms for administrative simplification in light of recent amendments to the General Administrative Procedure Law, 27444, and the recent Law of Prevention and Elimination of Bureaucratic Barriers, Legislative Decree 1256

al Estado. De este modo, no había razón suficiente para que ellas no tuvieran acceso a la información que se encontrara en poder de otra entidad.

En ese sentido, con la finalidad de alivianar la carga al administrado, por medio del nuevo artículo 39-A de la LPAG, se ha previsto que las entidades tienen la obligación de permitir a otras, gratuitamente, el acceso a sus bases de datos y registros para consultar sobre información requerida para el cumplimiento de requisitos de procedimientos administrativos o servicios prestados en exclusividad. De esta manera, en estos casos, la entidad únicamente solicitará al administrado la presentación de una declaración jurada en el cual manifieste que cumple con el requisito previsto en el procedimiento administrativo o servicio prestado en exclusividad.

Asimismo, lo mencionado anteriormente se encuentra complementado ${ }^{(11)}$ con el artículo 2 del Decreto Legislativo que aprueba diversas medidas de simplificación administrativa, 1246 (en adelante, el "Decreto Legislativo 1246"), el cual dispone que las entidades de la Administración Pública, de manera gratuita, a través de la interoperabilidad, interconecten, pongan a disposición, permitan el acceso o suministren la información o bases de datos actualizadas que administren, recaben, sistematicen, creen o posean respecto de los usuarios o administrados, que las demás entidades requieran necesariamente y de acuerdo a ley, para la tramitación de sus procedimientos administrativos y para sus actos de administración interna ${ }^{(12)}$.

A fin de que la implementación de la interoperabilidad sea progresiva, el artículo 3 de la norma mencionada establece que la siguiente información sea dispuesta, gratuitamente y permanente, a las entidades del Poder Ejecutivo, dentro del plazo máximo de sesenta (60) días hábiles computado a partir su publicación ${ }^{(13)}$ :

(11) Se debe tener en consideración que, anteriormente, la finalidad de interoperabilidad había sido regulada en el Decreto Supremo que crea la Plataforma de Interoperabilidad del Estado - PIDE, 083-2011-PCM; no obstante, esta finalidad no se ha visto del todo lograda, ni con resultados positivos y efectivos para los administrados. Por ello, se acierta en establecer la obligación de interoperabilidad por medio de una norma con rango legal.

(12) Artículo 2. Interoperabilidad entre entidades de la Administración Pública

Dispóngase que las entidades de la Administración Pública de manera gratuita, a través de la interoperabilidad, interconecten, pongan a disposición, permitan el acceso o suministren la información o bases de datos actualizadas que administren, recaben, sistematicen, creen o posean respecto de los usuarios o administrados, que las demás entidades requieran necesariamente y de acuerdo a ley, para la tramitación de sus procedimientos administrativos y para sus actos de administración interna. En los casos en los que la información o datos se encuentren protegidos bajo la Ley 29733, Ley de Protección de Datos Personales, las entidades de la Administración Pública deben obtener la autorización expresa e indubitable del usuario o administrado para acceder a dicha información o datos.

(13) Artículo 3. Implementación progresiva de la interoperabilidad en beneficio del ciudadano

3.1 Las entidades de la Administración Pública que posean y administren la información señalada en el numeral 3.2 del presente artículo deben ponerla a disposición de manera gratuita y permanente a las entidades del Poder Ejecutivo para la interoperabilidad a que hace referencia el artículo 2 del presente Decreto Legislativo, dentro del plazo máximo de sesenta (60) días hábiles computado a partir de la publicación de la presente norma.

3.2 La información de los usuarios y administrados que las entidades de la Administración Pública deben proporcionar a las entidades del Poder Ejecutivo de manera gratuita es:

- Identificación y estado civil;

- Antecedentes penales;

- Antecedentes judiciales;

- Antecedentes policiales;

- Grados y Títulos;

- Vigencia de poderes y designación de representantes legales;

- Titularidad o dominio sobre bienes registrados.

3.3 En tanto se implemente la interoperabilidad, la información y documentos mencionados en el numeral 3.2 precedente 


\section{Milagros Maraví}

(i) Identificación y estado civil.

(ii) Antecedentes penales.

(iii) Antecedentes judiciales.

(iv) Antecedentes policiales.

(v) Grados y Títulos.

(vi) Vigencia de poderes y designación de representantes legales.

(vii)Titularidad o dominio sobre bienes registrados.

En la misma línea, se precisa que, en tanto se implemente la interoperabilidad, dicha información y documentación podrán ser sustituidos, a opción del administrado o usuario, por declaración jurada, conforme a lo establecido en la LPAG.

De este modo, se puede evidenciar que las recientes modificaciones al ordenamiento tienen como enfoque establecer los cimientos de simplificación administrativa mínimos necesarios a fin de alivianar la carga del administrado en el cumplimiento de los diferentes requisitos para iniciar los procedimientos administrativos de su interés.

2.1.11 Precisiones respecto a la documentación prohibida de solicitar

Se ha reforzado la regulación de la documentación prohibida de solicitar, prevista en el artículo 40 de la LPAG, con el objetivo de que el administrado únicamente se encuentre obligado a presentar, ante las entidades, aquella que sea necesaria y no se encuentre en poder de la Administración Pública. Por ello, se encuentra como novedad la precisión de que las entidades están prohibidas de solicitar aquella documentación que la entidad solicitante genere o posea como producto del ejercicio de sus funciones públicas conferidas por la ley en virtud de algún trámite realizado anteriormente por el administrado en cualquiera de sus dependencias, o por haber sido fiscalizado por ellas, durante cinco (5) años anteriores inmediatos, siempre que los datos no hubieren sufrido variación. Si bien esta disposición siempre fue una finalidad de la LPAG, lamentablemente, las entidades no lo interpretaron de esa manera.

Igualmente, se realiza la precisión menor de que se encuentra prohibido de solicitar fotografías personales, salvo para obtener documentos de identidad, pasaporte o licencias o autorizaciones de índole personal, por razones de seguridad nacional y seguridad ciudadana. Además, se dispone que los administrados suministrarán ellos mismos las fotografías solicitadas o tendrán libertad para escoger la empresa que las produce, con excepción de los casos de digitalización de imágenes.

Por otro lado, se incorpora los siguientes supuestos de documentación prohibida de solicitar:

a) Aquella que, de conformidad con la normativa aplicable, se acreditó o debió acreditarse en una fase anterior o para obtener la culminación de un trámite anterior ya satisfecho.

b) Aquella que las entidades de la Administración Pública administren, recaben, sistematicen, creen o posean respecto de los usuarios o administrados que están obligadas a suministrar o poner a disposición de las demás entidades que las requieran para la tramitación de sus procedimientos administrativos y para sus actos de administración interna, de conformidad con lo dispuesto por ley, decreto legislativo o por decreto supremo refrendado por el PCM.

En el primer supuesto, se tutela el derecho del administrado, previsto en el numeral $126.2 \mathrm{del}$ artículo 126 de la LPAG, a que, en una única oportunidad, la Administración Pública debe requerir información al administrado a fin de subsanar las observaciones de la solicitud. Así, después de esta etapa, la documentación se entenderá acreditada para todos los efectos legales.

En el segundo supuesto, se tiene como objetivo proteger el derecho del administrado a que únicamente se le requiera información que

podrán ser sustituidos, a opción del administrado o usuario, por declaración jurada, conforme a lo establecido en la Ley 27444, Ley del Procedimiento Administrativo General. 
Mecanismos de simplificación administrativa a la luz de las recientes modificaciones a la Ley del Procedimiento Administrativo General, Ley 27444, y la reciente Ley de Prevención y Eliminación de Barreras Burocráticas, Decreto Legislativo 1256

Mechanisms for administrative simplification in light of recent amendments to the General Administrative Procedure Law, 27444, and the recent Law of Prevention and Elimination of Bureaucratic Barriers, Legislative Decree 1256

se encuentre o debería encontrarse en poder de las entidades. De este modo, se aliviana la carga del administrado respecto a la obligación de recolectar diversos requisitos para iniciar un procedimiento administrativo.

Adicionalmente, cabe señalar que si bien el artículo 5 del Decreto Legislativo $1246^{(14)}$, regula documentación prohibida de solicitar, se consideró conveniente que la LPAG también regule al respecto, toda vez que tiene como finalidad ser la norma general del procedimiento administrativo. De esta manera, ambas normas son complementarias entre sí, por lo que también se encuentra prohibido de solicitar la siguiente documentación:

a) Identificación y estado civil.

b) Antecedentes penales.

c) Antecedentes judiciales.

d) Antecedentes policiales.

e) Grados y Títulos.

f) Vigencia de poderes y designación de representantes legales.

g) Titularidad o dominio sobre bienes registrados.

h) Copia del Documento Nacional de Identidad (en adelante, “DNI").

i) Copias de Partida de Nacimiento o de Bautizo cuando se presente el DNI, excepto en los procedimientos donde resulte esencial acreditar la filiación y esta no pueda ser acreditada fehacientemente por otro medio. j) Copias de Partida de Nacimiento o Certificado de Defunción emitidas en fecha reciente o dentro de un periodo máximo, salvo en los procedimientos en ejercicio de la patria potestad(15).

k) Legalización notarial de firmas, salvo que se exija por ley expresa.

I) Copia de la ficha del Registro Único de Contribuyentes o certificado de información registrada en la Superintendencia Nacional de Aduanas y Administración Tributaria (en adelante, la "SUNAT").

m) Certificados o constancias de habilitación profesional o similares expedidos por los Colegios Profesionales, cuando dicha calidad pueda ser verificadas a través del respectivo portal institucional.

n) Cualquier otro requisito que acredite o proporcione información que conste en registros de libre acceso a través de internet u otro medio de comunicación pública.

Los siete primeros supuestos tratan de documentación que reiteradamente es solicitada en los procedimientos administrativos. Teniendo en cuenta que la información se encuentra en poder de las entidades, se ha dispuesto que deben ponerla a disposición de manera gratuita y permanente a las entidades del Poder Ejecutivo para la interoperabilidad(16). En los demás supuestos,

(14) En el punto 4.3 del presente artículo, evaluamos la propuesta de modificación del literal c) del artículo 5 y el artículo 7 del Decreto Legislativo 1246, de acuerdo al Proyecto de Ley 1082/2016-CR.

(15) La excepción fue prevista por medio de la Cuarta Disposición Complementaria Final del Decreto Legislativo que aprueba diversas medidas adicionales de simplificación administrativa, 1310.

(16) Artículo 3.- Implementación progresiva de la interoperabilidad en beneficio del ciudadano 3.1 Las entidades de la Administración Pública que posean y administren la información señalada en el numeral 3.2 del presente artículo deben ponerla a disposición de manera gratuita y permanente a las entidades del Poder Ejecutivo para la interoperabilidad a que hace referencia el artículo 2 del presente Decreto Legislativo, dentro del plazo máximo de sesenta (60) días hábiles computado a partir de la publicación de la presente norma. 
Milagros Maraví

se tiene como finalidad eliminar requisitos que no son fundamentales para la tramitación de los procedimientos administrativos, salvo que una ley lo disponga.

\subsubsection{Precisiones respecto a los documentos sucedáneos de los originales}

En el artículo 41 de la LPAG, se ha previsto que la presentación de documentos sucedáneos es de aplicación para todos los procedimientos administrativos, es decir, comprende tanto a los comunes como a los especiales. La anterior redacción de la norma permitía a las entidades interpretar que, por norma especial, podían disponer la entrega obligatoria de documentos originales, en el entendido de que la LPAG era de aplicación supletoria. En tal sentido, la modificación de la LPAG busca vetar esta interpretación a fin de simplificar los procedimientos administrativos en beneficio del administrado.

Además, se precisa que es considerado como sucedáneo la presentación de copias simples en reemplazo de documentos originales o copias legalizadas notarialmente de tales documentos, acompañadas de declaración jurada del administrado acerca de su autenticidad. En la misma línea, se ha establecido que el administrado podrá presentar como sucedáneo las expresiones escritas del administrado contenidas en declaraciones con carácter jurado mediante las cuales afirman su situación o estado favorable, así como la existencia, veracidad, vigencia en reemplazo de la información o documentación prohibida de solicitar.

En ambos casos, con la presentación de la declaración jurada, el administrado se estará comprometiendo a presentar información verdadera, de modo que, en caso se determine en una fiscalización posterior que otorgó información falsa en el procedimiento administrativo, entonces la entidad podría declarar de oficio la nulidad del acto administrativo.

Asimismo, teniendo en cuenta lo anterior, resulta coherente que el artículo 55 de la LPAG haya establecido que los administrados tienen derecho a (i) no presentar los documentos prohibidos de solicitar las entidades, y (ii) emplear los sucedáneos documentales.

2.1.13 Regulación sobre la validez de los actos administrativos y suspensión del procedimiento

Como se ha señalado anteriormente, en la tramitación de procedimientos administrativos, no es inusual que los administrados presenten actos administrativos emitidos por distintas entidades; sin embargo, en los hechos, se ha podido evidenciar que existen entidades que suelen cuestionar la validez de los mismos, pese a que, según el artículo IV del Título Preliminar de la LPAG, todos los actos administrativos gozan del Principio de Presunción de Veracidad.

Consecuentemente, con el objetivo de vetar esta situación y agilizar el procedimiento administrativo, se ha incorporado el artículo 41-A en la LPAG, el cual señala que, en la tramitación de procedimientos administrativos, las entidades no pueden cuestionar la validez de actos administrativos emitidos por otras entidades que son presentados

3.2 La información de los usuarios y administrados que las entidades de la Administración Pública deben proporcionar a las entidades del Poder Ejecutivo de manera gratuita es:

- Identificación y estado civil;

- Antecedentes penales;

- Antecedentes judiciales;

- Antecedentes policiales;

- Grados y Títulos;

- Vigencia de poderes y designación de representantes legales;

- Titularidad o dominio sobre bienes registrados.

3.3 En tanto se implemente la interoperabilidad, la información y documentos mencionados en el numeral 3.2 precedente podrán ser sustituidos, a opción del administrado o usuario, por declaración jurada, conforme a lo establecido en la Ley 27444, Ley del Procedimiento Administrativo General. 
Mecanismos de simplificación administrativa a la luz de las recientes modificaciones a la Ley del Procedimiento Administrativo General, Ley 27444, y la reciente Ley de Prevención y Eliminación de Barreras Burocráticas, Decreto Legislativo 1256

Mechanisms for administrative simplification in light of recent amendments to the General Administrative Procedure Law, 27444, and the recent Law of Prevention and Elimination of Bureaucratic Barriers, Legislative Decree 1256

para dar cumplimiento a los requisitos de los procedimientos administrativos a su cargo.

En razón a lo anterior, las entidades se encuentran prohibidas de suspender la tramitación de los procedimientos administrativos mientras se encuentran a la espera de resoluciones o información provenientes de otra entidad.

2.1.14 Precisiones respecto a la Presunción de Veracidad La Presunción de Veracidad ha constituido un gran avance respecto a la evaluación documental en los diferentes trámites ante las entidades, de manera que se evitaba los engorrosos trámites de autenticación de documento y los sobrecostos que implica tanto la legalización de documentos originales como el propio proceso de tramitación de los mismos (Martínez $2015,125)$.

Por ello, se ha realizado una importante precisión sobre los alcances de dicha presunción, a fin de sancionar únicamente a aquellos administrados que presentaron información falsa o inexacta. La redacción anterior del numeral 42.1 del artículo 42 de la LPAG señalaba, sin distinción, que todas las declaraciones juradas, los documentos sucedáneos presentados y la información incluida en los escritos y formularios que presenten los administrados para la realización de procedimientos administrativos "se presumen verificados por quien hace uso de ellos, así como de contenido veraz para fines administrativos, salvo prueba en contrario". Esa redacción tenía como consecuencia que se sancione a una persona no sólo por la información falsa o inexacta que ella hubiera producido o se refiera a su propia situación sino por la que se refiere a información de otros, incluso proveniente de otras autoridades.

En ese sentido, se ha modificado esta disposición para señalar que todas las declaraciones juradas, los documentos sucedáneos presentados y la información incluida en los escritos y formularios que presenten los administrados para la realización de procedimientos administrativos, se presumen verificados por quien hace uso de ellos, respecto a su propia situación, así como de contenido veraz para fines administrativos, salvo prueba en contrario.

Igualmente, se ha previsto que, en el caso de documentos emitidos por autoridades gubernamentales o por terceros, será suficiente con que el administrado acredite su debida diligencia con la presentación las verificaciones correspondientes y razonables, debido a que sería irrazonable solicitarle realizar acciones que están fuera de su alcance.

2.1.15 Precisiones sobre el derecho de tramitación y los gastos administrativos

Se han realizado diversas precisiones al artículo 44 de la LPAG con respecto al derecho de tramitación. En primer lugar, se señala que son condiciones para la procedencia del cobro del derecho de tramitación que éstos hayan sido aprobados conforme al marco legal vigente y que estén consignados en el TUPA vigente, dado que éste constituye una garantía sobre aquello que es exigible para el administrado.

En segundo lugar, se dispone que mediante decreto supremo refrendado por la PCM y el Ministerio de Economía y Finanzas (en adelante, "MEF"), se precisa los criterios, procedimientos y metodologías para la determinación de los costos de los procedimientos, y servicios administrativos que brinda la administración y para la fijación de los derechos de tramitación. En este supuesto, la aplicación de dichos criterios, procedimientos y metodologías es obligatoria para la determinación de costos de los procedimientos administrativos y servicios prestados en exclusividad para todas las entidades públicas en los procesos de elaboración o modificación del TUPA. Sin embargo, puede darse el caso de que las entidades requieran un monto menor por el derecho de tramitación; por ello, se les permite aprobar derechos de tramitación menores a los que resulten de la aplicación de los criterios, procedimientos y metodologías aprobados.

Por otro lado, la redacción anterior del artículo 45 de la LPAG señalaba que para que el costo del derecho de tramitación sea superior a una UIT, se requería acogerse a un régimen 
Milagros Maraví

de excepción, el cual iba a ser establecido mediante decreto supremo refrendado por la PCM y el MEF; sin embargo, con la redacción vigente, bastará la autorización de la PCM. No obstante, esta autorización no es aplicable en los casos en que dicha entidad haya aprobado derechos de tramitación para los procedimientos estandarizados.

2.1.16 Incorporación de la tercerización de actividades El artículo 49-A de la LPAG es una novedad en nuestro ordenamiento, puesto que permite a las entidades que terceros realicen las diferentes actividades vinculadas a los procedimientos administrativos y servicios prestados en exclusividad. De esta manera, esta nueva disposición tiene como objetivo facilitar el cumplimiento de sus funciones y lograr que sean más eficientes, lo cual, a su vez beneficia al administrado.

No obstante, la tercerización no será aplicable a las actividades que comprenden la emisión de los actos administrativos o cualquier resolución. Ello es debido a que éstos producen efectos jurídicos sobre los intereses, obligaciones o derechos de los administrados en una situación concreta, de manera que la entidad está en mejor posición para conocer la normativa y así evitar cualquier perjuicio ilegal o irrazonable contra el administrado.

2.1.17 Precisiones respecto a las facultades de solicitar información y formular consultas

Las facultades de solicitar información y formular consultas están relacionadas directamente con el derecho de petición. En razón a ello, se han incorporado precisiones en los artículos 110 y 111 de la LPAG a fin de que se mejore la atención de los derechos y requerimientos ciudadanos frente al accionar de la Administración Pública.

En ese sentido, el artículo 110 de la LPAG señala que las entidades pueden utilizar mecanismos electrónicos para responder las solicitudes de información por parte de los administrados. Así, se libera al administrado de tener que realizar una solicitud física y apersonarse ante la entidad a fin de presentar dicha solicitud.

Asimismo, se precisa, en los artículos 110 y 111 de la LPAG, que las entidades están obligadas a responder la solicitud de información o consulta, respectivamente, dentro del plazo legal. Lo anterior es debido a que la práctica nos ha demostrado que existen entidades que se demoran irrazonablemente en dar respuesta a estas solicitudes.

2.1.18 Flexibilización para la representación del administrado

La redacción original del artículo 115 de la LPAG establecía que, para la tramitación ordinaria de los procedimientos, era necesario un poder general formalizado mediante simple designación de persona cierta en el escrito o acreditando una carta poder con firma del administrado. Como se puede evidenciar, la primera forma de representación era tediosa, puesto que el administrado que necesitaba un representante tenía que tramitar, ante registros públicos, la inscripción de un poder general. Si bien la segunda forma es más sencilla, no era de extrañar que las entidades no requieran un poder simple sino un poder legalizado.

Teniendo en cuenta lo anterior, la modificación a este artículo ha tenido como finalidad flexibilizar aún más la representación del administrado. Por ello, se ha dispuesto que es suficiente carta poder simple con firma del administrado, salvo que leyes especiales requieran una formalidad adicional.

De esta manera, se aliviana la carga al administrado a efectos de que pueda ser representado en la tramitación de los procedimientos administrativos.

2.1.19 Precisiones respecto al derecho de acceso al expediente

La redacción anterior del título del artículo 160 de la LPAG se refería al acceso a la información del expediente, mientras que la modificación únicamente señala el acceso al expediente. Si bien es una modificación sutil, los efectos permiten garantizar la tutela de los derechos de los administrados. Así, la redacción anterior permitía entender, erróneamente, que los administrados tenían derecho a una parte de la información del expediente; no obstante, lo 
Mecanismos de simplificación administrativa a la luz de las recientes modificaciones a la Ley del Procedimiento Administrativo General, Ley 27444, y la reciente Ley de Prevención y Eliminación de Barreras Burocráticas, Decreto Legislativo 1256

Mechanisms for administrative simplification in light of recent amendments to the General Administrative Procedure Law, 27444, and the recent Law of Prevention and Elimination of Bureaucratic Barriers, Legislative Decree 1256

anterior no es propio de un Estado Constitucional de Derecho, dado que el administrado tiene el derecho a conocer todo el expediente que se elabora en razón de un tema que produce efectos jurídicos sobre éste. En razón a ello, se ha modificado el título a fin de que sea comprensible que el administrado tiene derecho a acceder a todo el expediente.

De igual manera, se precisa que el pedido de acceso al expediente puede realizarse verbalmente, sin necesidad de solicitarlo mediante el procedimiento de transparencia y acceso a la información pública, siendo concedido de inmediato. Sobre el particular, la práctica ha demostrado que diversas entidades ponen por encima la burocracia antes que el derecho del administrado, de manera que le solicitan una solicitud escrita o, inclusive, que realice la solicitud por medio del procedimiento de transparencia y acceso a la información pública. En ese sentido, la modificación realizada tiene como finalidad que los administrados cuenten con la garantía de que las entidades se encuentran legalmente obligadas a permitir el acceso del expediente sin imposición de ningún requisito formal.

2.1.20 Cambios en la regulación sobre la pérdida de ejecutoriedad del acto administrativo

Entre las características de los actos administrativos, se encuentra la ejecutoriedad, la cual es "una especial manifestación de la eficacia de los mismos, por lo cual ello, cuando imponen deberes o restricciones a los particulares, pueden ser realizados aun contra su voluntad por los órganos directos de la Administración, sin que sea necesaria la previa intervención de la acción declaratoria de los órganos jurisdiccionales" (Zanobini 1954-373).

No obstante, por un lado, la Administración Pública no puede estar siempre a la espera de que el administrado cumpla lo resuelvo por ella sin realizar ningún acto $\mathrm{y}$, por otro lado, el administrado no puede estar a la espera de ser siempre perseguido a fin de cumplir con lo dispuesto por la Administración Pública. Por ello, se modifica el artículo 193 de la LPAG con el objetivo de establecer que el acto administrado pierde efectividad y ejecutoriedad a los dos (2) años de haber obtenido firmeza, sin que la Administración Pública haya iniciado los actos que le competen para ejecutarlos. Esta modificación no tiene como finalidad tutelar el incumplimiento de los administrados, sino, por el contrario, que la Administración Pública active todas las acciones de su competencia a fin de hacer cumplir aquello que haya resuelto en el menor tiempo posible $y$, de esta manera, obtener seguridad jurídica en el ordenamiento.

2.1.21 Interposición de recursos administrativos A fin de que el administrado interponga un recurso administrativo, se ha eliminado el requisito de firma de abogado en el artículo 211 de la LPAG. De esta manera, el administrado no tendrá que incurrir en gastos adicionales a efectos de poder cuestionar una decisión de la Administración Pública que le causa perjuicio.

\subsection{Simplificación del procedimiento administrativo sancionador}

Al igual que en el procedimiento administrativo de la parte general de la LPAG, se ha considerado necesario también establecer mecanismos de simplificación administrativa en el procedimiento administrativo sancionador.

2.2.1 Prescripción de la infracción administrativa y la exigibilidad de las multas En el numeral 233.2 del artículo 233 de la LPAG, se ha establecido nuevas reglas para el cómputo del plazo de prescripción de las infracciones administrativas. Así, se dispone que dicho cómputo comenzará a partir del día en que la infracción se hubiera cometido en el caso de las infracciones instantáneas o infracciones instantáneas de efectos permanentes; desde el día que se realizó la última acción constitutiva de la infracción en el caso de infracciones continuadas; o desde el día en que la acción cesó en el caso de las infracciones permanentes.

Sobre el particular, se debe tener en consideración que, siguiendo a Baca Oneto,en las infracciones instantáneas, la lesión o puesta en peligro del bien jurídico protegido se produce en un momento determinado, en el que la infracción se consuma, sin producir una situación antijurídica duradera. Asimismo, las infracciones instantáneas con 
efectos permanentes son aquellas que producen un estado de cosas contrario al ordenamiento jurídico, que se mantiene; aunque los efectos de la conducta infractora sean duraderos y permanezcan en el tiempo, la consumación de ésta es instantánea. Igualmente, en las infracciones continuadas, se realizan diferentes conductas, cada una de las cuales constituye por separado una infracción, pero que se consideran como una única infracción, siempre y cuando formen parte de un proceso unitario. También, las infracciones permanentes son aquellas en las cuales el administrado se mantiene en una situación infractora, cuyo mantenimiento le es imputable; no obstante, no son los efectos jurídicos de la conducta infractora los que persisten, sino la conducta misma (Baca 2012, 268-9).

En la misma línea, se ha hecho precisiones sobre los mecanismos por los cuales se puede declarar la prescripción de la infracción administrativa. La versión anterior del numeral 233.3 del artículo 233 de la LPAG únicamente permitía que los administrados planteen la prescripción por vía de defensa y la autoridad debía resolverla sin más trámite que la constatación de los plazos. Si bien ello era correcto, con la modificación realizada, la Administración Pública también tiene un rol activo, puesto que tiene la obligación de declarar de oficio la prescripción y dar por concluido el procedimiento cuando advierta que se ha cumplido el plazo para determinar la existencia de infracciones.

Por otro lado, se ha incorporado el artículo 233-A en la LPAG, el cual regula la prescripción de la exigibilidad de las multas impuestas. Al respecto, las multas que son impuestas por las entidades deben ser cumplidas, pero esa decisión, en cuanto limita el ejercicio de ciertos derechos, o la libre disposición de determinados bienes, no debe ser exigible siempre. Por ello, se dispone que la facultad de una autoridad de exigir, vía ejecución forzosa, el pago de multas impuestas por la comisión de una infracción administrativa prescribe en el plazo fijado en las leyes especiales aplicables. Sin embargo, si en esas normas no hubiese determinación alguna, entonces la prescripción operará concluido el término de dos (2) años, contados a partir de que se presenten alguna de las siguientes circunstancias:

a) Que haya quedado firme el acto mediante el cual se impuso la multa, o se puso fin a la vía administrativa.

b) Que el proceso contencioso administrativo destinado a la impugnación del acto mediante el cual se impuso la multa haya concluido con carácter de cosa juzgada en forma desfavorable para el administrado.

Igualmente, se precisa que el cómputo del plazo de prescripción de la exigibilidad de multas se suspende cuando se inicia el procedimiento de ejecución forzosa. No obstante, si se suspende esa ejecución forzosa, o se paraliza el procedimiento por más de veinticinco (25) días hábiles, se reanuda el cómputo. Al igual que con las infracciones administrativas, se permite solicitar la prescripción como medio de defensa dentro del procedimiento de ejecución forzosa.

De este modo, si la prescripción es deducida en sede administrativa, el plazo máximo para resolver sobre la solicitud de suspensión de la ejecución forzosa por prescripción es de ocho (8) días hábiles, contados a partir de la presentación de dicha solicitud por el administrado. Vencido dicho plazo sin que exista pronunciamiento expreso, entonces se entenderá concedida la solicitud, por aplicación del silencio administrativo positivo.

2.2.2 Incorporación de condiciones eximentes y atenuantes de responsabilidad

El artículo 236-A de la LPAG ha sido modificado a fin de regular condiciones eximentes y atenuantes de responsabilidad. Así, en el primer caso, se incorporan las siguientes condiciones eximentes de responsabilidad por la comisión de infracciones:

a) El caso fortuito o la fuerza mayor debidamente comprobada.

b) Obrar en cumplimiento de un deber legal o el ejercicio legítimo del derecho de defensa.

c) La incapacidad mental debidamente comprobada por la autoridad competente, siempre que esta afecte la aptitud para entender la infracción. 
Mecanismos de simplificación administrativa a la luz de las recientes modificaciones a la Ley del Procedimiento Administrativo General, Ley 27444, y la reciente Ley de Prevención y Eliminación de Barreras Burocráticas, Decreto Legislativo 1256

Mechanisms for administrative simplification in light of recent amendments to the General Administrative Procedure Law, 27444, and the recent Law of Prevention and Elimination of Bureaucratic Barriers, Legislative Decree 1256

d) La orden obligatoria de autoridad competente, expedida en ejercicio de sus funciones.

e) El error inducido por la Administración o por disposición administrativa confusa o ilegal.

f) La subsanación voluntaria por parte del posible sancionado del acto u omisión imputado como constitutivo de infracción administrativa, con anterioridad a la notificación de la imputación de cargos.

Todos los supuestos mencionados, salvo el último, se producen sin que exista culpa del administrado, toda vez que se tratan de circunstancias ajenas a éste. De esta manera, son razones que justifican válidamente la realización de acciones u omisiones en contra del cumplimiento de las obligaciones solicitadas por el ordenamiento.

Además, cabe señalar que los dos (2) últimos supuestos eran considerados como atenuantes de responsabilidad en la redacción anterior del artículo 236-A de la LPAG. Sin embargo, es jurídicamente correcto que sean condiciones eximentes. Por un lado, el administrado no hubiera incurrido en la infracción si la Administración Pública no le hubiera inducido en error o si no existiera una disposición administrativa confusa o ilegal. Por otro lado, la subsanación voluntaria del acto u omisión, antes de la notificación de la imputación de cargos, incentiva a los administrados a reparar el daño que hayan producido a consecuencia del incumplimiento; sin embargo, consideramos que el daño debe ser reparado totalmente, de manera que no exista ningún bien jurídico protegido vulnerado.

En la misma línea, se regulan nuevas condiciones atenuantes de responsabilidad:

a) Si iniciado un procedimiento administrativo sancionador el infractor reconoce su responsabilidad de forma expresa y por escrito. En los casos en que la sanción aplicable sea una multa esta se reduce hasta un monto no menor de la mitad de su importe. b) Otros que se establezcan por norma especial.

En el primer caso, se otorga el beneficio al administrado de poder disminuir la multa hasta un máximo del cincuenta por ciento $(50 \%)$ si reconoce la comisión de la infracción; para ello, el reconocimiento debe realizarse expresamente y por escrito. Sobre el particular, el ordenamiento nos permite evidenciar que hay entidades que establecen el porcentaje de la reducción de la multa según la etapa del procedimiento administrativo sancionador en la cual el administrado reconoce su incumplimiento(17).

Igualmente, se autoriza a las entidades para que puedan establecer otras condiciones atenuantes de responsabilidad, toda vez que cada una de ellas tiene conocimiento suficiente sobre aquellas medidas que son necesarias, en su respectivo sector, a fin de disminuir los efectos de la comisión de la infracción por parte del administrado.

2.2.3 Regulación de la caducidad del procedimiento administrativo sancionador Otra novedad es la regulación de la caducidad del procedimiento sancionador en el nuevo artículo 237-A de la LPAG. Al respecto, la doctrina señala que la caducidad en el procedimiento sancionador es aquella que opera como un plazo máximo de duración de éste (con excepción de los supuestos de suspensión), pasado el cual se extingue, y debe entenderse como nunca iniciado, sin perjuicio de la facultad administrativa de iniciar uno nuevo si la infracción no ha prescrito (Baca 2011, 266). Además, debe tenerse en cuenta que la existencia de un

(17) Por ejemplo, el artículo 30-A del Reglamento General de Supervisión, Fiscalización y Sanción de las Empresas Prestadoras de Servicios de Saneamiento, aprobado por Resolución de Consejo Directivo № 003-2007-SUNASS-CD y modificado por la Resolución de Consejo Directivo N 004-2017-SUNASS-CD, dispone que la Superintendencia Nacional de Servicios de Saneamiento reducirá la multa en cincuenta por ciento (50\%) si el reconocimiento se realiza con la presentación de descargos; en treinta por ciento (30\%) hasta antes de la notificación del informe final de instrucción; en diez por ciento (10\%) hasta el quinto día hábil posterior a la notificación del informe final de instrucción. 
Milagros Maraví

procedimiento administrativo sancionador implica un perjuicio en el administrado, dado que se está evaluando la posible imposición de una sanción. De esta manera, éste no puede estar siempre a la espera para conocer la decisión de la Administración Pública.

En razón a lo anterior, se ha previsto que las entidades tienen el plazo de nueve (9) meses para resolver los procedimientos sancionadores iniciados de oficio; sin embargo, dicho plazo puede ser ampliado excepcionalmente, mediante resolución escrita y motivada emitida por el órgano competente. También se dispone que, en caso la ley establezca un plazo mayor para resolver, entonces la caducidad operará al vencimiento de éste.

Asimismo, este plazo no es aplicable para los procedimientos recursivos, de modo que debe interpretarse que la autoridad de primera instancia es aquella la que cuenta con dicho plazo máximo a efectos de resolver el procedimiento administrativo sancionador.

Adicionalmente, se establece que, transcurrido el plazo máximo para resolver sin que se notifique la resolución respectiva, se entenderá, en los casos en que corresponda, caducado el procedimiento y se procederá a su archivo. Sin perjuicio de ello, en el supuesto en el cual la infracción no hubiera prescrito, el órgano competente deberá evaluar el inicio de un nuevo procedimiento sancionador, debiendo tenerse presente que el procedimiento caducado no interrumpe la prescripción.

Al igual que en la declaración de prescripción de la infracción administrativa, se señala que esta caducidad podría ser declarada de oficio por el órgano competente, lo cual no descarta que sea solicitada por el administrado si la autoridad pertinente no efectuó tal declaración.

\subsection{Empoderamiento de la Presidencia del Consejo de Ministros}

En nuestro ordenamiento, necesitamos de una autoridad que no sólo asesore a las diversas entidades en temas de simplificación administrativa, sino que también las fiscalice, de manera que se evidencie una efectiva desburocratización. Si bien en la versión original del artículo 48 de la LPAG disponía que la PCM tenía a su cargo garantizar el cumplimiento de la disposiciones de esta ley en todas las entidades de la Administración Pública, la práctica demostró que contaba con pocas herramientas para ello.

En ese sentido, la modificación al artículo 48 de la LPAG tiene como finalidad emporar a la PCM para que, como entidad rectora, tenga un alcance multisectorial. Para ello, se ha tomado en consideración lo previsto en el artículo 3 de la Política Nacional de Modernización de la Gestión Pública, aprobado por Decreto Supremo 004-2013-PCM, el cual señala que la PCM, a través de la Secretaría de la Gestión Pública, es el rector del proceso de Modernización de la Gestión Pública y tiene a su cargo la articulación, seguimiento y evaluación de la Política Nacional de Modernización de la Gestión Pública ${ }^{(18)}$.

En razón a ello, el artículo 48 de la LPAG vigente dispone que la PCM, como entidad rectora, es la máxima autoridad técnica normativa del Sistema de Modernización de la Gestión Pública. Al respecto, el artículo 44 de la Ley Orgánica del Poder ejecutivo, Ley 29158, dispone que los Sistemas están a cargo de un ente rector que se constituye en su autoridad técnico-normativa a nivel nacional; dicta las normas y establece los procedimientos relacionados con su ámbito; coordina su operación técnica y es responsable de su correcto funcionamiento en el marco de la esta ley, sus leyes especiales y disposiciones complementarias $^{(19)}$.

(18) Artículo 3. Rol de la Secretaría de Gestión Pública de la Presidencia del Consejo de Ministros La Presidencia del Consejo de Ministros, a través de la Secretaría de Gestión Pública, en su calidad de rector del proceso de Modernización de la Gestión Pública y en coordinación con otras entidades cuando por la materia a desarrollar ello sea necesario, tendrá a su cargo la articulación, seguimiento y evaluación de la Política Nacional de Modernización de la Gestión Pública.

(19) Artículo 44. Entes Rectores 
Mecanismos de simplificación administrativa a la luz de las recientes modificaciones a la Ley del Procedimiento Administrativo General, Ley 27444, y la reciente Ley de Prevención y Eliminación de Barreras Burocráticas, Decreto Legislativo 1256

Mechanisms for administrative simplification in light of recent amendments to the General Administrative Procedure Law, 27444, and the recent Law of Prevention and Elimination of Bureaucratic Barriers, Legislative Decree 1256

Teniendo en cuenta lo anterior, la LPAG ha acertado en otorgar las siguientes competencias a la PCM:

a) Dictar directivas, metodologías y lineamientos técnico normativos en las materias de su competencia.

b) Emitir opinión vinculante sobre el alcance e interpretación de las normas de simplificación administrativa. En el caso de los TUPA de los Ministerios y Organismos Públicos, tiene competencia para emitir opinión previa favorable a su aprobación.

c) Supervisar que las entidades cumplan con aprobar sus TUPA conforme a la normativa aplicable.

d) Supervisar que las entidades cumplan con aplicar los procedimientos estandarizados y actualicen sus TUPA para incorporarlos en él.

e) Supervisar que las entidades cumplan con las normas de simplificación administrativa en la tramitación de sus procedimientos administrativos y servicios prestados en exclusividad.

f) Detectar los incumplimientos a las normas de la LPAG y ordenar las modificaciones pertinentes, otorgando a las entidades un plazo perentorio para la subsanación. No obstante, en caso de no producirse la subsanación, la PCM entrega un informe a la Comisión de Eliminación de Barreras Burocráticas del INDECOPI, a fin de que inicie de oficio un procedimiento de eliminación de barreras burocráticas, sin perjuicio de la aplicación de lo previsto en el artículo 239 de la LPAG, con respecto a la responsabilidad administrativa.

Igualmente, a lo largo de la LPAG, se puede identificar nuevas competencias de la PCM a fin de implementar la simplificación administrativa en los procedimientos administrativos:

a) Calificar procedimientos administrativos como de aprobación automática o sujetos a evaluación previa, en cuyo caso se aplicará el silencio administrativo positivo o el silencio administrativo negativo. De esta manera, la calificación que realice será de obligatorio cumplimiento a partir del día siguiente de su publicación en el Diario Oficial "El Peruano", por todas las entidades.

b) Aprobar procedimientos administrativos estandarizados, así como ampliar la relación de documentos originales que pueden ser reemplazados por sucedáneos.

c) Precisar, por medio de decreto supremo refrendado junto al MEF, los criterios, procedimientos y metodologías para la determinación de los costos de los procedimientos, y servicios administrativos que brinda la administración y para la fijación de los derechos de tramitación. También, se señala que la aplicación de dichos criterios, procedimientos y metodologías es obligatoria para la determinación de costos de los procedimientos administrativos y servicios prestados en exclusividad para todas las entidades públicas en los procesos de elaboración o modificación del TUPA de cada entidad. Sin perjuicio de lo anterior, la entidad puede aprobar derechos de tramitación menores a los que resulten de la aplicación de los criterios, procedimientos y metodologías aprobados.

d) Aprobar, por medio de decreto supremo, los lineamientos que sean necesarios para la condena de costas y costos por la interposición de recursos administrativos maliciosos o temerarios en los procedimientos trilaterales.

Los Sistemas están a cargo de un Ente Rector que se constituye en su autoridad técnico-normativa a nivel nacional; dicta las normas y establece los procedimientos relacionados con su ámbito; coordina su operación técnica y es responsable de su correcto funcionamiento en el marco de la presente Ley, sus leyes especiales y disposiciones complementarias. 
Milagros Maraví

Con estas nuevas herramientas de la PCM, consideramos que un sistema así permite identificar problemas al interior de las entidades y solucionarlos antes de que se llegue al punto de perjudicar a los administrados, así como determinar la existencia de trabas administrativas y la presentación de denuncias. Además, un sistema así es mucho más conveniente tanto para la Administración Pública como para los administrados (Maraví 2000, 293).

\section{Ley de Prevención y Eliminación de Barreras Burocrátícas, aprobada por Decreto Legislativo 1256}

La función de la Comisión de Eliminación de Barreras Burocráticas del INDECOPI (en adelante, la "Comisión") es importante en nuestro ordenamiento, toda vez permite que la regulación sea compatible con las libertades de iniciativa privada y de empresa, demostrando que el procedimiento de eliminación de barreras burocráticas tiene una sólida base dentro de la Constitución Política (Ochoa 2014, 50).

Al respecto, recientemente, se publicó en el Diario Oficial "El Peruano", la Ley de Eliminación de Barreras Burocráticas, la cual refuerza las funciones de prevención, fiscalización y sanción de la Comisión. Así, de acuerdo al artículo 1 de esta norma, tiene por objeto supervisar el cumplimiento del marco legal que protege los derechos a la libre iniciativa privada y la libertad de empresa, en beneficio de las personas naturales o jurídicas, mediante la prevención o eliminación de barreras burocráticas ilegales que obstaculicen el acceso de los agentes económicos en los mercados o que constituyan incumplimientos de las normas que garantizan la simplificación administrativa.

Asimismo, como se podrá evidenciar más adelante, la Ley de Eliminación de Barreras Burocráticas toma en consideración las recomendaciones de la OCDE con respecto a otorgar a la Comisión mayor independencia. De igual manera, se toman medidas adicionales a efectos de obtener la modificación o eliminación de la regulación que dio origen a la generación de quejas por parte de los ciudadanos (OCDE 2016, 158).

A continuación presentaremos las novedades de la Ley de Eliminación de Barreras Burocráticas para eliminar y prevenir las barreras burocráticas:

\subsection{Compilación de la regulación de barreras burocráticas}

El principal aporte de esta norma se basa en la compilación de la diferente normativa que regulaba la eliminación de barreras burocráticas en un solo cuerpo legal. Anteriormente, se encontraba en el artículo 26BIS de la Ley de Organización y Funciones del Instituto Nacional de Defensa de la Competencia y de la Protección de Propiedad Intelectual - INDECOPI, aprobado por Decreto Ley 25868, el Decreto Legislativo que refuerza las facultades sobre eliminación de barreras burocráticas para el fomento de la competitividad, 1212, el artículo 48 de la LPAG, los precedentes de observancia obligatoria previstas en las Resoluciones No. 182-97-TDC y No. 188-97-TDC, entre otras.

Así, la Ley de Eliminación de Barreras Burocráticas regula de manera general (i) la definición de barrera burocrática, (ii) el procedimiento administrativo, (iii) la metodología de identificación de barreras burocráticas, (iv) el régimen sancionador y correctivo, y (v) las actividades de persuasión.

De este modo, consideramos que esta compilación coadyuva a la simplificación administrativa, puesto que uno de sus fines es reducir la cantidad de normas en el ordenamiento, de manera que únicamente se emitan aquellas que presenten calidad regulatoria.

\subsection{Incorporación de Principios}

La Ley de Eliminación de Barreras Burocráticas presenta como otra novedad la incorporación principios no recogidos en la normativa anterior. Así, el Principio de Acción Preventiva se encuentra vinculado con la acción de prevención de la Comisión, de manera que las entidades que hayan establecido barreras burocráticas y que, por las acciones de prevención e inspección del INDECOPI, hayan 
Mecanismos de simplificación administrativa a la luz de las recientes modificaciones a la Ley del Procedimiento Administrativo General, Ley 27444, y la reciente Ley de Prevención y Eliminación de Barreras Burocráticas, Decreto Legislativo 1256

Mechanisms for administrative simplification in light of recent amendments to the General Administrative Procedure Law, 27444, and the recent Law of Prevention and Elimination of Bureaucratic Barriers, Legislative Decree 1256

decidido eliminarlas voluntariamente, no se verán afectadas por un procedimiento de oficio contra ellas, privilegiándose dicha corrección.

Por otro lado, el Principio de Encausamiento señala que la Comisión o la Secretaría Técnica, como órganos de primera instancia, identifican de oficio otros medios de materialización de una barrera burocrática distintos a los indicados en la denuncia interpuesta, cuando sea evidente su existencia. En razón a ello, un aspecto importante es que los referidos órganos podrán identificar de oficio la barrera burocrática cuestionada en el texto íntegro de la denuncia y no únicamente del petitorio.

\subsection{Efectos de las resoluciones del INDECOPI}

Entre las recomendaciones de la OCDE, se encuentra la toma de medidas adicionales a efectos de la modificación o eliminación de la regulación que dio origen a la generación de quejas por parte de los ciudadanos. Por ello, el artículo 8 de la Ley de Eliminación de Barreras Burocráticas ha incorporado la eliminación de barreras burocráticas ilegales con efectos generales. Así, cuando en un procedimiento iniciado a pedido de parte o de oficio, la Comisión o la Sala declare la ilegalidad de barreras burocráticas materializadas en disposiciones administrativas, se dispone su inaplicación con efectos generales. Para ello, se necesita de la publicación del extracto de la resolución de la Comisión o la Sala en el Diario Oficial "El Peruano".

No obstante, también puede darse el caso que, después de lo mencionado anteriormente, nuevamente se presente una denuncia por la misma barrera burocrática ilegal. En este supuesto, la Comisión encausará el escrito presentado como una denuncia informativa de incumplimiento de mandato. De esta manera, aquel que haya presentado la denuncia ya no tendrá que sobrellevar el procedimiento administrativo regular, dado que la actuación de la Comisión será más expeditiva.

Por otro lado, se mantienen los alcances de los efectos de la declaración de barreras burocráticas en actos administrativos y actuaciones materiales. Se establece que cuando en un procedimiento iniciado a pedido de parte, la Comisión o la Sala declare la ilegalidad o carencia de razonabilidad de barreras burocráticas materializadas en actos administrativos y/o actuaciones materiales, será su inaplicación al caso concreto en favor del denunciante.

\subsection{Establecimiento de plazos}

Se ha previsto que el procedimiento seguido ante la Comisión tiene una duración máxima de ciento veinte (120) días hábiles. El mismo plazo aplica para el procedimiento seguido ante la Sala. Así, hay predictibilidad en el plazo para que las solicitudes de inaplicación de barreras burocráticas sean resueltas.

3.5 Limitaciones para la interposición de demandas del Estado contra el Estado

Otro aporte de la Ley de Eliminación de Barreras Burocráticas es la limitación para la interposición de demandas contenciosoadministrativas de entidades del Poder Ejecutivo contra las resoluciones del INDECOPI. Al respecto, la práctica nos demostró que dichas entidades interponían demandas a fin de cuestionar las decisiones del INDECOPI, de manera que los ciudadanos tenían que esperar la emisión de una sentencia con calidad de cosa juzgada a fin de obtener los beneficios de la declaración de una barrera burocrática ilegal o irrazonable. De este modo, se tiene como objetivo evitar la judicialización de casos del Estado contra el Estado.

Sin embargo, excepcionalmente, se aceptarán dichas demandas. Para ello, las entidades demandantes deberán pasar por un doble filtro, el cual consiste en conseguir, en primer lugar, la autorización de su máxima autoridad $y$, en segundo lugar, la aprobación de la PCM. Solo de esta manera las entidades se encontrarán facultadas a cuestionar las resoluciones del INDECOPI.

\subsection{Facultad del INDECOPI para acudir al Poder Judicial}

La redacción original del artículo 48 de la LPAG señalaba que la Comisión podía interponer demanda de acción popular contra barreras burocráticas contenidas en decretos supremos, a fin de lograr su modificación o derogación y, con el mismo propósito, acudir a la Defensoría del Pueblo para que se 
Milagros Maraví

interponga la demanda de inconstitucionalidad contra barreras burocráticas contenidas en normas municipales y regionales de carácter general, que tengan rango de ley.

Si bien lo anterior ha sido recogido en el artículo 11 de la Ley de Eliminación de Barreras Burocráticas, esta norma precisa que el INDECOPI puede interponer la demanda de acción popular, en los procedimientos iniciados de oficio, contra decretos supremos $u$ otras normas de inferior jerarquía que contengan barreras burocráticas identificadas como ilegales y/o carentes de razonabilidad, a fin de lograr su derogación o nulidad.

\subsection{Sanciones a los funcionarios y a las entidades}

Respecto al régimen sancionador y correctivo, las sanciones que imponga el INDECOPI pueden recaer en funcionarios y servidores públicos, así como en entidades.

Así pues, el funcionario, el servidor público o cualquier persona que ejerza función administrativa por delegación, puede ser sancionada por la Comisión con multas de hasta veinte (20) UIT en los siguientes supuestos:

a) Cuando incumpla el mandato de inaplicación de la barrera burocrática declarada ilegal con efectos generales o caso en concreto.

b) Cuando luego de publicada, en el Diario Oficial "EI Peruano", la resolución que declara la barrera burocrática irrazonable resuelto en un procedimiento de oficio, aplique u ordene aplicar la barrera burocrática previamente declarada carente de razonabilidad, o cuando pudiendo disponer su inaplicación, omita hacerlo.

c) Cuando luego de publicado lo resuelto en los procedimientos de oficio iniciados con anterioridad a la Ley de Eliminación de Barreras Burocráticas, aplique u ordene aplicar la barrera burocrática previamente declarada ilegal y/o carente de razonabilidad, o cuando pudiendo disponer su inaplicación, omita hacerlo.

d) Cuando incumpla el mandato de inaplicación de la barrera burocrática declarada ilegal y/o carente de razonabilidad en un procedimiento iniciado de parte tramitados con las normas que regían la materia antes de la vigencia de la Ley de Eliminación de Barreras Burocráticas.
Sobre el particular, consideramos que se establece una multa cuantiosa debido a que las conductas infractoras de las entidades perjudican el objetivo central de las medidas de simplificación administrativa, ya que lo que se busca es erradicar aquella regulación que presenta, en los hechos, una traba ilegal o irrazonable.

En la misma línea, la Comisión o la Sala, de ser el caso, puede imponer a las entidades multas de hasta veinte (20) UIT cuando verifique que alguno de sus funcionarios, servidores públicos o cualquier persona que ejerza en su nombre, función administrativa por delegación, bajo cualquier régimen laboral o contractual, aplica u ordena la aplicación de barreras burocráticas.

Adicionalmente, la Ley de Eliminación de Barreras Burocráticas dispone que la gradualidad de sanciones está sujeta a criterios como la gravedad del daño ocasionado, la reincidencia y/o continuidad de la comisión de la infracción, y la intencionalidad de la conducta.

3.8 Actividades de prevención y persuasión La Ley de Eliminación de Barreras ha tomado en consideración la técnica de regulación responsiva, la cual consiste, principalmente, en que el regulador escale gradualmente una pirámide de cumplimiento (enforcement pyramid) al momento de buscar el cumplimiento de la norma, comenzando, desde la base, con acciones de persuasión, hasta llegar a la cumbre con medidas más punitivas o sancionadoras, según el tipo de respuesta y compromiso que pueda obtener del sujeto regulado (Ochoa 2016, 166).

Así, según el artículo 46 de la Ley de Eliminación de Barreras Burocráticas, el INDECOPI privilegia las acciones de prevención y/o coordinación, a efectos de promover la eliminación voluntaria de las barreras burocráticas por parte de las entidades sujetas a investigación. Para ello, la Comisión y/o su Secretaría Técnica puede 
Mecanismos de simplificación administrativa a la luz de las recientes modificaciones a la Ley del Procedimiento Administrativo General, Ley 27444, y la reciente Ley de Prevención y Eliminación de Barreras Burocráticas, Decreto Legislativo 1256

Mechanisms for administrative simplification in light of recent amendments to the General Administrative Procedure Law, 27444, and the recent Law of Prevention and Elimination of Bureaucratic Barriers, Legislative Decree 1256

solicitar toda la información o documentación que consideren necesarias para el cumplimiento de las actividades descritas, a través de cartas, oficios o cualquier otro medio escrito, físico o electrónico. De esta manera, como mencionamos anteriormente, esta labor está vinculada directamente con el nuevo Principio de Acción Preventiva.

Igualmente, el INDECOPI tiene una función persuasiva, mediante la cual, de acuerdo al artículo 48 de esta norma, puede elaborar y difundir un ranking de entidades según el nivel de cumplimiento de las normas en materia de eliminación de barreras burocráticas ${ }^{(20)}$.

Asimismo, en aplicación del artículo 49 de la Ley de Eliminación de Barreras Burocráticas, si el INDECOPI durante un procedimiento identifica un requisito, limitación o exigencia que pueda restringir el desarrollo de una actividad económica o los principios que garantizan la simplificación administrativa, puede disponer que su respectiva Secretaría Técnica emita una opinión a través de un informe técnico, mediante el cual se recomienden medidas para promover la eliminación de dichos obstáculos.

Otra actividad de persuasión es el reporte de acciones tomadas para la eliminación de barreas burocráticas, prevista en el artículo 59 de la norma mencionada. Al respecto, las entidades que hayan sido denunciadas en los procedimientos seguidos ante el INDECOPI, cuyas resoluciones hayan quedado firmes, deben comunicar al INDECOPI sobre las medidas adoptadas respecto a lo resuelto por la Comisión(21).

\section{Procedimientos administrativos en cuestionamiento}

Durante el periodo de delegación de facultades de la Ley que delega en el Poder Ejecutivo la facultad de legislar en materia de reactivación económica y formalización, seguridad ciudadana, lucha contra la corrupción, agua y saneamiento y reorganización de Petroperú S.A., Ley 30506, se emitieron diversos decretos legislativos que podrían ser cuestionables en su cumplimiento con la simplificación administrativa o la nueva normativa de la LPAG.

En razón a ello, analizaremos la inaplicación de la LPAG al Código Tributario, la aplicación del Principio de Culpabilidad en los procedimientos sancionadores especiales y el cuestionamiento del Decreto Legislativo 1246 por parte de la Comisión de Constitución y Reglamento del Congreso de la República.

4.1 Inaplicación de la Ley del Procedimiento Administrativo General, Ley 27444, al Código Tributario

El artículo 1 del Decreto Legislativo que modifica el Código Tributario, 1311 (en adelante, el "Decreto Legislativo 1311"), dispone que esta norma tiene por objeto modificar el Código Tributario aprobado por el Decreto Legislativo 816, a fin de corregir situaciones inequitativas para los contribuyentes y adecuar sus disposiciones a los estándares internacionales emitidos por la OCDE sobre el intercambio de información para fines tributarios.

Pese a tener dicha finalidad, la Quinta Disposición Complementaria Final del Decreto Legislativo 1311 señala que la SUNAT, el Tribunal Fiscal y otras administraciones tributarias se rigen supletoriamente por la LPAG, de manera que no se les aplica el numeral 1 y 2 del artículo II del Título Preliminar de la LPAG. Asimismo, estas entidades se sujetarán a los principios de la potestad sancionadora previstos en los artículos 168 y 171 del Código Tributario, por lo que no será de aplicación el artículo 230 de la LPAG.

(20) Al respecto, se ha emitido la Directiva para la implementación de los Rankings de entidades de la Administración Pública en materia de Barreras Burocráticas, aprobada por Resolución de la Presidencia del Consejo Directivo del INDECOPI No. 020-2017-INDECOPI-COD.

(21) Sobre el particular, se ha emitido la Directiva sobre el Reporte de Acciones Adoptadas por las Entidades para la Eliminación de Barreras Burocráticas y el Formato de Reporte de Acciones Adoptadas para la Eliminación de Barreras Burocráticas, aprobada por Resolución de la Presidencia del Consejo Directivo del INDECOPI No. 018-2017-INDECOPI-COD. 
Así, la exposición de motivos del Decreto Legislativo 1311 sustenta la existencia de esta disposición en los problemas de notificación, el procedimiento administrativo sancionador, el procedimiento contencioso tributario de reclamo, el procedimiento de inscripción en el Registro para el Control de los Bienes Fiscalizados, y la prescripción de la infracción.

Al respecto, consideramos que la Quinta Disposición Complementaria Final del Decreto Legislativo 1311 no sólo vulnera los derechos y las garantías mínimos de los administrados previstos en la LPAG, sino que también es inconstitucional por las razones que explicaremos a continuación.

\subsubsection{Notificación de los actos administrativos}

La exposición de motivos del Decreto Legislativo 1311 señala que mientras la LPAG establece sólo tres (3) modalidades de notificación en orden de prelación, el Código Tributario regula más modalidades y permite su utilización indistintamente en función de las necesidades del acto a notificar. Además, para permitir el uso de notificación electrónica, la LPAG requiere previo consentimiento expreso del administrado; no obstante, el Código Tributario no exige el consentimiento al deudor tributario para la notificación electrónica.

Sobre el particular, consideramos que crear la obligación en el administrado de tener un correo electrónico por cada entidad no coadyuva a la simplificación administrativa, ya que se genera la carga en éste de tener que revisar cada correo y, de esta manera, tomar conocimiento de las decisiones de las entidades.

Sin perjuicio de ello, se debe tener en cuenta que todos los ciudadanos tienen obligaciones tributarias, de manera que la SUNAT, por medio de la notificación electrónica de la Clave SOL, ha encontrado la vía idónea para notificar la gran cantidad de actos administrativos que emite. Por ello, no sería eficiente, ni eficaz la notificación personal, prevista en el inciso 20.1.1 del numeral 20.1 del artículo 20 de la LPAG. No obstante, lo anterior no contraviene la LPAG, en la medida de que, por orden de prelación, se debería realizar la notificación electrónica en caso no se pueda la notificación personal.

\subsubsection{Procedimiento administrativo sancionador} La exposición de motivos del Decreto Legislativo 1311 indica que aplicar los principios, la estructura y las garantías previstas en la LPAG tendría los siguientes efectos: a) Generaría mayor burocracia y demandaría mayor tiempo para la imposición de sanciones. Así, conforme al artículo 165 del Código Tributario, las infracciones se determinan de manera objetiva y la resolución de multa se emite con una sola configuración; sin embargo, la LPAG requiere que una autoridad instructora le notifique la imputación de cargos para iniciar un procedimiento sancionador y que otra autoridad le imponga la sanción.

b) Al aplicar el principio de retroactividad benigna conllevaría a que no se puedan expedir normas que flexibilicen las sanciones tributarias, pues extinguiría deudas tributarias por concepto de multas de grandes empresas cuyos casos se encuentran pendiente de resolver por el Tribunal Fiscal y el Poder Judicial. Por tanto, esta medida resta eficacia al régimen sancionador tributaria.

c) Se tendría que observar los supuestos de eximentes y atenuantes, los cuales no existen en el procedimiento sancionador tributario.

En primer lugar, es preciso señalar que el Código Tributario cumple con el requerimiento previsto en el numeral 10 del artículo 230 de la LPAG, con respecto a que, por medio de una ley o un decreto legislativo, se dispone la responsabilidad objetiva del administrado en el procedimiento sancionador. Sin perjuicio de ello, el requerimiento de la existencia de una autoridad instructora y una autoridad que decide la aplicación de la sanción es esencial a fin garantizar el derecho al debido procedimiento del administrado. Así, el Tribunal Constitucional ha afirmado que "el debido proceso, como principio constitucional, está concebido como el cumplimiento de todas las garantías y normas de orden público que deben aplicarse a todos los casos y procedimientos, incluidos los administrativos, a fin de que las personas estén en condiciones de defender adecuadamente sus 
Mecanismos de simplificación administrativa a la luz de las recientes modificaciones a la Ley del Procedimiento Administrativo General, Ley 27444, y la reciente Ley de Prevención y Eliminación de Barreras Burocráticas, Decreto Legislativo 1256

Mechanisms for administrative simplification in light of recent amendments to the General Administrative Procedure Law, 27444, and the recent Law of Prevention and Elimination of Bureaucratic Barriers, Legislative Decree 1256

derechos ante cualquier acto del Estado que pueda afectarlos"(22). Igualmente, precisa que el debido proceso "presenta dos expresiones: la formal y la sustantiva. En la de carácter formal, los principios y reglas que lo integran tienen que ver con las formalidades estatuidas, tales como las que establecen el juez natural, el procedimiento preestablecido, el derecho de defensa y la motivación; y en su expresión sustantiva, están relacionados los estándares de razonabilidad y proporcionalidad que toda decisión judicial debe suponer"(23).

De esta manera, es necesario que el administrado tenga conocimiento, por medio de una autoridad instructora, el inicio de un procedimiento administrativo a efectos de que pueda defenderse contra la posible imposición de una sanción. Mediante de la imputación de cargos, se permite al administrado informarse cabalmente de los hechos calificados como ilícitos y otra información relevante, como por ejemplo, la calificación de los hechos, posibles sanciones, entre otros (Morón 2014, 801). Igualmente, es indispensable que sea otra autoridad la que, a partir de la información obtenida por la autoridad instructora y el administrado, resuelva el procedimiento sancionador.

"La segregación o separación de las fases de instrucción y de aplicación de sanción (...) pretende especializar al primero en la indagación e investigación y al segundo en permitir su mayor independencia para ponderar los hechos. (...) La imparcialidad y objetividad suponen que el órgano a quien compete decidir un asunto, no tenga una posición preconcebida, que pueda influirlo a decidir en una determinada forma (imparcialidad subjetiva), de manera que no queda satisfecho el referido principio cuando en la fase decisoria interviene, activamente, quien ha adelantado opinión sobre el caso que le corresponde decidir" (Morón 2005, 6).

En segundo lugar, si bien el principio de retroactividad benigna se encuentra reconocida en el numeral 5 del artículo 230 de la LPAG, se debe señalar que este principio no sólo está reconocido en la LPAG, sino se trata de un principio constitucional que irradia todo nuestro ordenamiento, de manera que no puede ser desconocido por el argumento erróneo de no poder recaudar mayor cantidad de montos dinerarios por concepto de deudas tributarias. Al respecto, el Tribunal Constitucional ha señalado que la retroactividad benigna "no puede ser interpretado desde la perspectiva exclusiva de los intereses del penado", sino que "debe ser interpretado a partir de una comprensión institucional integral, es decir, a partir de una aproximación conjunta de todos los valores constitucionalmente protegidos que resulten relevantes en el asunto que es materia de evaluación"(24). En razón a ello, el principio de retroactividad benigna no sólo es aplicable en el proceso penal, sino en todo procedimiento administrativo sancionador, incluidos los tributarios.

En tercer lugar, los supuestos eximentes y atenuantes de la responsabilidad son aplicables a todos los procedimientos especiales, dado que pueden ocurrir circunstancias que justifiquen la conducta u omisión infractora. De este modo, la SUNAT se encuentra en la obligación de analizar los casos en concreto para, a partir de la información obtenida, determinar si el administrado se encuentra en alguno de los supuestos eximentes o atenuantes de responsabilidad, dado que éstos implicarían el rompimiento del nexo causal de la comisión de la infracción.

4.1.3 Procedimiento Contencioso Tributario - Reclamos

La exposición de motivos del Decreto Legislativo 1311 señala que si solo se aplican los procedimientos previstos en las leyes especiales en la parte que sean más favorables a los administrados, se generaría incertidumbre respecto a si el procedimiento contencioso tributario de reclamación sería un recurso de reconsideración. En caso fuera así, indica que podría tener los siguientes efectos:

(22) Fundamento 2 de la Sentencia del Tribunal Constitucional expedida bajo el Expediente No. 4289-2004-AA/TC.

(23) Fundamento 43 de la Sentencia del Tribunal Constitucional expedida bajo el Expediente No. 0023-2005-PI/TC.

(24) Fundamento52 de la Sentencia del Tribunal Constitucional expedida bajo el Expediente No. 0019-2005-PI/TC. 
Milagros Maraví

a) Quedaría la duda si el procedimiento de reclamo sea opcional y si se necesita la presentación de prueba nueva.

b) El Código Tributario establece que el procedimiento de reclamo se resuelve en el plazo de nueve (9) meses; no obstante, al aplicar la LPAG, quedaría la duda si la SUNAT deba resolver en treinta (30) días hábiles y si al vencimiento de este plazo, se suspenderían los intereses moratorios.

c) Si se interpone un reclamo, quedaría la duda sobre la aplicación del literal b) del numeral 218.2 del artículo 218 de la LPAG.

Por otro lado, se afirma que si bien la LPAG dispone que la revocación de actos administrativos debe ser emitida por la máxima autoridad de la entidad, la SUNAT está facultada para señalar los casos en los que se puede revocar, con lo cual ya estaría garantizando lo previsto por la LPAG.

Sobre el particular, el procedimiento contencioso tributario de reclamo tiene naturaleza distinta al procedimiento de reconsideración, aunque presentan ciertas similitudes. En ese sentido, sería correcto que el procedimiento contencioso tributario de reclamo sea obligatorio; sin perjuicio de ello, no exigir la presentación de prueba nueva para su interposición, consistiría en otorgar una condición más favorable al administrado que aquella prevista en la LPAG.

Para la revocación de actos administrativos, el numeral 203.1.4 del artículo 203 de la LPAG requiere el desarrollo de procedimiento previo, toda vez que el administrado tiene derecho a ejercer su derecho de defensa a fin de cuestionar o aceptar la revocación. Además, se dispone que sea la más alta autoridad de la entidad la cual declare la revocación debido a que la responsabilidad no debe recaer en el mismo nivel emisor por las consecuencias que de tal decisión se derivan, y debe tenerse en cuenta que la declaración de revocación agota la vía administrativa (Morón 2011, 440). En ese sentido, no es suficiente con que el Código Tributario regule las causales de revocación, sino que es necesario que se garantice que el administrado tendrá derecho a ejercer su derecho de defensa en un procedimiento previo y que quién resuelva el procedimiento sea la más alta autoridad de la SUNAT.

4.1.4 Procedimientos de aprobación automática en el Registro para el Control de los Bienes Fiscalizados
La exposición de motivos del Decreto Legislativo 1311indica que la aprobación automática de la solicitud en el Registro para el Control de los Bienes Fiscalizados afecta el control de los bienes fiscalizados, en tanto pueden ser transportados y comercializados únicamente si están inscritos en dicho registro.

En este caso, el problema del control de los bienes fiscalizados no se encuentra en la calificación de aprobación automática de la solicitud de inscripción en el Registro para el Control de los Bienes Fiscalizados, sino en los requisitos que se han previsto para este procedimiento. Si los requisitos previstos en el Anexo A del Reglamento del Decreto Legislativo 1126, Decreto Legislativo que establece medidas de control en los insumos químicos y productos fiscalizados, maquinarias y equipos utilizados para la elaboración de drogas ilícitas, aprobado por Decreto Supremo 044-2013-EF, no son suficientes, entonces es tarea pendiente de la SUNAT determinar requisitos idóneos para controlar los bienes fiscalizados.

Sumado a lo anterior, se debe tener en consideración que la SUNAT puede realizar fiscalización posterior del procedimiento de inscripción, de manera que se encuentra facultada para declarar la nulidad del registro en caso se compruebe el fraude o la falsedad en la declaración o información presentada, de acuerdo al numeral 32.3 del artículo 32 de la LPAG.

\subsubsection{Prescripción}

La exposición de motivos del Decreto Legislativo 1311 señala que el Código Tributario prevé distintos supuestos en los que se suspende o interrumpe la prescripción, y teniendo en cuenta la cantidad de procesos que se genera en la cobranza, sería materialmente imposible revisar cada expediente de oficio para determinar la prescripción. 
Mecanismos de simplificación administrativa a la luz de las recientes modificaciones a la Ley del Procedimiento Administrativo General, Ley 27444, y la reciente Ley de Prevención y Eliminación de Barreras Burocráticas, Decreto Legislativo 1256

Mechanisms for administrative simplification in light of recent amendments to the General Administrative Procedure Law, 27444, and the recent Law of Prevention and Elimination of Bureaucratic Barriers, Legislative Decree 1256

Sobre el particular, la SUNAT tiene competencia para regular en qué supuestos se suspende o interrumpe la prescripción siempre que respete lo previsto en el artículo 233 de la LPAG. Sin perjuicio de ello, la dejadez no puede ser razón suficiente para justificar que la SUNAT no debe declarar, de oficio, la prescripción de infracciones, sino que tiene que esperar la solicitud del administrado. Al respecto, la doctrina ha señalado que la prescripción debe declararse de oficio (Caballero 1991, 443). Esto es debido a que la Administración Pública tiene conocimiento directo de los procedimientos sancionadores de los administrados, así que se encuentra en mejor posición para organizarse y resolver los procedimientos sancionadores en los plazos establecidos, así como para determinar en qué casos se ha cumplido el plazo de prescripción de la infracción administrativa. En caso contrario, se estaría tutelando la inacción en el cumplimiento de sus funciones, en vez de actuar de manera tal que se evidencie que está al servicio del ciudadano.

\subsection{El Principio de Culpabilidad en los procedimientos} administrativos especiales

De acuerdo al numeral 10 del artículo 230 de la LPAG, el Principio de Culpabilidad es un principio de la potestad sancionadora de la Administración Pública. En razón al mismo, la responsabilidad administrativa es subjetiva, salvo los casos en que por ley o decreto legislativo se disponga la responsabilidad administrativa objetiva.

Si bien dicha disposición establece una excepción para la aplicación de la responsabilidad subjetiva, se ha podido evidenciar que se ha aprovechado el periodo de delegación de facultades para emitir decretos legislativos que disponen la responsabilidad objetiva. En otros casos, se ha previsto la aplicación de responsabilidad subjetiva y objetiva.

4.2.1 Responsabilidad objetiva en procedimientos administrativos especiales En el siguiente cuadro, presentamos los decretos legislativos que se emitieron para establecer la responsabilidad objetiva del administrado:

\begin{tabular}{|c|c|c|}
\hline Entidad & Norma & Regulación: responsabilidad objetiva \\
\hline \multirow[t]{3}{*}{$\begin{array}{l}\text { Instituto Nacional de Defensa de la } \\
\text { Competencia y de la Protección de } \\
\text { la Propiedad Intelectual - INDECOPI }\end{array}$} & \multirow{2}{*}{$\begin{array}{l}\text { Decreto Legislativo que aprueba Disposiciones Com- } \\
\text { plementarias a la Decisión } 486 \text { de la Comisión de la } \\
\text { Comunidad Andina que establece el Régimen Común } \\
\text { sobre Propiedad Industrial, } 1075 . \\
\text { Disposiciones modificadas por el Decreto Legislativo } \\
\text { de simplificación de los Procedimientos Administrativos } \\
\text { en materia de propiedad intelectual seguidos ante los } \\
\text { órganos resolutivos del Instituto Nacional de Defensa } \\
\text { de la Competencia y de la Protección de la Propiedad } \\
\text { Intelectual - INDECOPI, } 1309 .\end{array}$} & $\begin{array}{l}\text { Artículo 97.- Actos de infracción. } \\
\text { (...) La responsabilidad administrativa derivada de los } \\
\text { actos de infracción a los derechos de propiedad industrial } \\
\text { es objetiva. }\end{array}$ \\
\hline & & $\begin{array}{l}\text { Artículo 98.- Competencia desleal. } \\
\text { (...) En los supuestos contemplados en el presente } \\
\text { artículo la responsabilidad administrativa es objetiva. }\end{array}$ \\
\hline & $\begin{array}{l}\text { Ley sobre el Derecho de Autor, Decreto Legislativo } 822 . \\
\text { Disposición modificada por el Decreto Legislativo de } \\
\text { simplificación de los Procedimientos Administrativos } \\
\text { en materia de propiedad intelectual seguidos ante los } \\
\text { órganos resolutivos del Instituto Nacional de Defensa } \\
\text { de la Competencia y de la Protección de la Propiedad } \\
\text { Intelectual - INDECOPI, } 1309 .\end{array}$ & $\begin{array}{l}\text { Artículo 183.- Se considera infracción la vulneración } \\
\text { de cualquiera de las disposiciones contenidas en la } \\
\text { presente ley. } \\
\text { La responsabilidad administrativa derivada de los actos } \\
\text { de infracción a la legislación en materia de derecho de } \\
\text { autor y derechos conexos es objetiva. }\end{array}$ \\
\hline
\end{tabular}


Milagros Maraví

\begin{tabular}{|l|l|}
\hline $\begin{array}{l}\text { Autoridad Nacional de Protección de } \\
\text { Datos Personales }\end{array}$ & $\begin{array}{l}\text { Ley de protección de datos personales, Ley } 29733 . \\
\text { Disposición modificada por el Decreto Legislativo que } \\
\text { crea la Autoridad Nacional de Transparencia y Acceso } \\
\text { a la Información Pública, fortalece el régimen de protec- } \\
\text { ción de datos personales y la regulación de la gestión } \\
\text { de intereses, 1353. }\end{array}$
\end{tabular}

Artículo 38.- Tipificación de infracciones

(...) Los administrados son responsables objetivamente por el incumplimiento de obligaciones derivadas de las normas sobre protección de datos personales.

de intereses, 1353

\subsubsection{Responsabilidad subjetiva y objetiva en procedimientos} administrativos especiales

A continuación presentaremos los casos en que se ha dispuesto la aplicación de la responsabilidad subjetiva y objetiva en los procedimientos sancionadores:

\begin{tabular}{|c|c|c|}
\hline Entidad & Norma & Regulación: responsabilidad objetiva y subjetiva \\
\hline $\begin{array}{l}\text { Organismo Supervisor de las Contrata- } \\
\text { ciones del Estado - OSCE }\end{array}$ & $\begin{array}{l}\text { Ley de Contrataciones del Estado, Ley } 30225 \\
\text { Disposición modificada por el Decreto Legislativo } \\
\text { que modifica la Ley } 30225 \text {, Ley de Contrataciones } \\
\text { del Estado, } 1341 .\end{array}$ & $\begin{array}{l}\text { Artículo 50. Infracciones y sanciones Administrativas } \\
50.1 \text { El Tribunal de Contrataciones del Estado sanciona a } \\
\text { los proveedores, participantes, postores, contratistas y/o } \\
\text { subcontratistas, cuando corresponda, incluso en los casos } \\
\text { a que se refiere el literal a) del artículo } 5 \text { de la presente Ley, } \\
\text { cuando incurran en las siguientes infracciones: (...) } \\
\text { La responsabilidad derivada de las infracciones previstas en } \\
\text { este artículo es objetiva, salvo en aquellos tipos infractores } \\
\text { que admitan la posibilidad de justificar la conducta. }\end{array}$ \\
\hline $\begin{array}{l}\text { Superintendencia de Banca, Seguros y } \\
\text { Administradoras Privadas de Fondos de } \\
\text { Pensiones }\end{array}$ & $\begin{array}{l}\text { Decreto Legislativo que modifica el primer párrafo } \\
\text { de la Octava Disposición Complementaria Final } \\
\text { del Decreto Legislativo } 1275,1349\end{array}$ & $\begin{array}{l}\text { DISPOSICIONES COMPLEMENTARIAS FINALES } \\
\text { Primera.- Reglas para los procedimientos administrativos } \\
\text { sancionadores iniciados por la Superintendencia de } \\
\text { Banca, Seguros y Administradoras Privadas de Fondos } \\
\text { de Pensiones. } \\
\text { En los procedimientos administrativos sancionadores } \\
\text { iniciados por la Superintendencia de Banca, Seguros y } \\
\text { Administradoras Privadas de Fondos de Pensiones se } \\
\text { aplican las siguientes reglas: } \\
\text { a) Para las infracciones calificadas como leves, la respon- } \\
\text { sabilidad administrativa es subjetiva. } \\
\text { b) Para el caso de las infracciones graves y muy graves, la } \\
\text { responsabilidad administrativa es objetiva. } \\
\text { La Superintendencia reglamenta la debida aplicación de } \\
\text { esta responsabilidady su observancia en los procedimientos } \\
\text { sancionadores. }\end{array}$ \\
\hline
\end{tabular}


Mecanismos de simplificación administrativa a la luz de las recientes modificaciones a la Ley del Procedimiento Administrativo General, Ley 27444, y la reciente Ley de Prevención y Eliminación de Barreras Burocráticas, Decreto Legislativo 1256

Mechanisms for administrative simplification in light of recent amendments to the General Administrative Procedure Law, 27444, and the recent Law of Prevention and Elimination of Bureaucratic Barriers, Legislative Decree 1256

4.2.3 Inexistencia de consenso sobre la responsabilidad administrativa subjetiva u objetiva

A partir de las normas presentadas, se puede apreciar que no hay consenso sobre la aplicación de la responsabilidad subjetiva u objetiva en los procedimientos administrativos sancionadores de la Administración Pública.

No obstante lo anterior, se debe tener en consideración que el Tribunal Constitucional ha reconocido el Principio de Culpabilidad en el derecho administrativo sancionador en diversa jurisprudencia. Así, ha señalado que constituye "un límite a la potestad sancionadora del Estado está representado por el principio de culpabilidad"(25). Igualmente, considera que "(...) que los principios de culpabilidad, legalidad, tipicidad, entre otros, constituyen principios básicos del derecho sancionador, que no sólo se aplican en el ámbito del derecho penal, sino también en el del derecho administrativo sancionador (...)"(26).

En razón a lo anterior, ha afirmado que:

"11. (...) conviene precisar que el objeto del procedimiento administrativo sancionador es investigar $y$, de ser el caso, sancionar supuestas infracciones cometidas como consecuencia de una conducta ilegal por parte de los administrados. Si bien la potestad de dictar sanciones administrativas al igual que la potestad de imponer sanciones penales, derivan del ius puniendi del Estado, no pueden equipararse ambas, dado que no sólo las sanciones penales son distintas a las administrativas, sino que los fines en cada caso son distintos (reeducación y reinserción social en el caso de las sanciones penales y represiva en el caso de las administrativas). A ello hay que agregar que en el caso del derecho administrativo sancionador, la intervención jurisdiccional es posterior, a través del proceso contencioso administrativo o del proceso de amparo, según corresponda.
12. No obstante la existencia de estas diferencias, existen puntos en común, pero tal vez el más importante sea el de que los principios generales del derecho penal son de recibo, con ciertos matices, en el derecho administrativo sancionador. Sin agotar el tema, conviene tener en cuenta cuando menos algunos de los que son de recibo, protección y tutela en sede administrativa: (...)

c. Principio de culpabilidad, que establece que la acción sancionable debe ser imputada a título de dolo o culpa, lo que importa la prohibición de la responsabilidad objetiva; esto es, que solo se puede imponer una sanción si es que la conducta prohibida y su consecuencia están previstas legalmente.

En el caso del derecho penal, es más sencillo apreciar cómo opera este principio, puesto que además de la tipificación realizada en el Código Penal y de indicarse las sanciones que se pueden imponer a título de culpa o dolo, se establecen los parámetros necesarios para que la sanción no resulte arbitraria o desproporcionada (mínimos y máximos).

$(\ldots)^{\prime \prime 2}(27)$.

En ese sentido, la aplicación de la responsabilidad subjetiva del administrado es la regla en los procedimientos administrativos sancionadores, de modo que únicamente podría disponerse la responsabilidad

(25) Sentencia del Tribunal Constitucional expedida bajo el Expediente No. 2868-2004-AA/TC. Fundamento 21. http://www. tc.gob.pe/jurisprudencia/2005/02868-2004-AA.html (consultada el 9 de enero de 2017).

(26) Sentencia del Tribunal Constitucional expedida bajo el Expediente No. 2050-2002-AA/TC. Fundamento 8. http://www.tc.gob. pe/jurisprudencia/2003/02050-2002-AA.html (consultada el 9 de enero de 2017).

Sentencia del Tribunal Constitucional. expedida bajo el Expediente No. 2192-2004-AA/TC. Fundamento 4. http://www.tc.gob. pe/jurisprudencia/2005/02192-2004-AA.html (consultada el 9 de enero de 2017).

(27) Sentencia del Tribunal Constitucional. expedida bajo el Expediente No. 01873-2009-PA/TC. Fundamentos 11 y 12 . http:// www.tc.gob.pe/jurisprudencia/2010/01873-2009-AA.html (consultada el 9 de enero de 2017). 
Milagros Maraví

administrativa objetiva cuando, a partir de la propia naturaleza del procedimiento administrativo sancionador correspondiente, se determine que es suficiente la configuración de la conducta o la omisión del administrado para cometer la infracción. A todas luces lo mencionado anteriormente implicará que las entidades realicen un análisis concienzudo de los procedimientos administrativos sancionadores para sustentar por qué correspondería aplicar la responsabilidad objetiva.

Por lo mencionado, consideramos que las entidades deberían realizar el esfuerzo de analizar y determinar si, de acuerdo a la naturaleza del procedimiento administrativo sancionador de su competencia, sería aplicable la responsabilidad subjetiva u objetiva. Únicamente cuando existan razones suficientes, la entidad debería realizar los actos necesarios para que se emita la ley o el decreto legislativo que disponga la aplicación de la responsabilidad objetiva del administrado.

\subsection{Prohibición de exigir la presentación de copia de partida de nacimiento y certificado de defunción, y la autorización para realizar actos con Documento Nacional de Identidad vencido}

Por medio del Proyecto de Ley 1082/2016-CR, la Comisión de Constitución y Reglamento del Congreso de la República recomienda la modificación del literal c) del artículo 5 y el artículo 7 del Decreto Legislativo 1246, toda vez que estarían vulnerando el Principio de Seguridad Jurídica.

4.3.1 Prohibición de exigir la presentación de copia de partida de nacimiento y certificado de defunción

El literal c) del artículo 5 del Decreto Legislativo 1246 establece que las entidades de la Administración Pública están prohibidas de exigir a los administrados o usuarios, en el marco de un procedimiento o trámite administrativo, copias de partida de nacimiento o certificado de defunción, emitidas en fecha reciente o dentro de un periodo máximo ${ }^{(28)}$. Por su lado, la Comisión de Constitución y Reglamento recomienda que se precise, en este literal, que la exigencia de un periodo máximo razonable de emisión será establecida mediante decreto supremo en tutela del Principio de Seguridad Jurídica.

Sobre el particular, consideramos que el literal c) del artículo 5 del Decreto Legislativo 1246 vigente es correcto, toda vez que, mientras no opere la interoperabilidad entre las entidades, no será necesario que el administrado presente copias de la partida de nacimiento o el certificado de defunción de fecha reciente o dentro de un periodo máximo. Por ello, la Comisión de Constitución y Reglamento yerra en recomendar precisar que el periodo máximo será previsto por medio de un decreto supremo, dado que, en todo caso, dicha precisión debería estar en una disposición transitoria. De esta manera, una vez que se implemente la interoperabilidad, carecerá de sentido que las entidades soliciten copias de los documentos mencionados independientemente de la fecha en la cual hayan sido emitidos, toda vez que, en caso sea necesario realizar una actualización, las entidades tendrán acceso a esa información.

Consecuentemente, la Comisión de Constitución y Reglamento ha perdido la oportunidad de poder recomendar una modificación que en verdad coadyuve a la simplificación administrativa en los procedimientos administrativos.

4.3.2 Autorización para realizar actos con Documento Nacional de Identidad vencido

El artículo 7 del Decreto Legislativo 1246 dispone que el vencimiento de la fecha de vigencia del DNI no constituye impedimento para la participación del ciudadano en actos

(28) Artículo 5. Prohibición de la exigencia de documentación 5.1 Las entidades de la Administración Pública están prohibidas de exigir a los administrados o usuarios, en el marco de un procedimiento o trámite administrativo, los siguientes documentos: (...)

c) Copias de Partida de Nacimiento o Certificado de Defunción emitidas en fecha reciente o dentro de un periodo máximo. $(\ldots)$ 
Mecanismos de simplificación administrativa a la luz de las recientes modificaciones a la Ley del Procedimiento Administrativo General, Ley 27444, y la reciente Ley de Prevención y Eliminación de Barreras Burocráticas, Decreto Legislativo 1256

Mechanisms for administrative simplification in light of recent amendments to the General Administrative Procedure Law, 27444, and the recent Law of Prevention and Elimination of Bureaucratic Barriers, Legislative Decree 1256

civiles, comerciales, administrativos, notariales, registrales, judiciales, policiales y, en general, para todos aquellos casos en que deba ser presentado para acreditar su identidad(29).

No obstante, la Comisión de Constitución y Reglamento considera que este artículo socava el Principio de Seguridad Jurídica y vacía materialmente de contenido la obligatoriedad de renovar el DNI cada ocho (8) años de acuerdo al artículo 37 de la Ley Orgánica del Registro Nacional de Identificación y Estado Civil, Ley $26497^{(30)}$; igualmente, sostiene que existen elementos en el DNI que únicamente pueden ser actualizados a pedido de parte y por decisión del titular, como son la huella, la firma y la foto. Por ello, esta comisión recomienda que se precise que se puede utilizar el DNI vencido por un plazo no mayor a sesenta (60) días calendarios, contados a partir de la fecha de vencimiento del DNI, sin perjuicio de la obligación de proceder a su posterior renovación.

Con respecto a esta propuesta de modificación, consideramos que el artículo 7 no contraviene el Principio de Seguridad Jurídica, dado que éste debe ser entendido como la "aptitud para predecir los acontecimientos jurídicos y de darle a éstos un curso estable, como la de controlar y neutralizar los riesgos que el sistema jurídico debe afrontar" (Sagués 1997, 218). En ese orden de ideas, la utilización del DNI vencido no tendría incidencia en el principio mencionado.

Sin perjuicio de lo anterior, la Comisión de Constitución y Reglamento acierta en afirmar que existen elementos en el DNI que únicamente son actualizados a pedido de parte y por decisión del titular. Con el paso del tiempo, el rostro de la persona cambia y ésta también puede decidir cambiar de firma, por lo que sí resulta necesario que se establezca un plazo máximo para la utilización del DNI vencido.

\section{Conclusiones}

La LPAG modificada por el Decreto Legislativo 1272, y la Ley de Eliminación de Barreras Burocráticas han recogido las recomendaciones de la OCDE en temas de simplificación administrativa. De esta manera, se ha implementado en el ordenamiento peruano, el procedimiento administrativo electrónico, los procedimientos administrativos estandarizados, la regla de la vigencia indeterminada de los títulos habilitantes, la obligación de interoperabilidad entre las entidades, entre otros. Consideramos que las novedades de la LPAG tendrán como consecuencia inmediata alivianar las cargas impuestas en el administrado en un procedimiento administrativo. Además, lo anterior necesitaba ser complementado con el empoderamiento de la PCM, en su calidad de ente rector del Sistema de Modernización de la Gestión Pública. Por ello, se le ha otorgado diversas competencias a efectos de que implemente mecanismos adicionales de simplificación administrativa y supervise el cumplimiento por parte de las entidades.

En la misma línea, la Ley de Eliminación de Barreras Burocráticas tiene como objetivo reforzar las facultades de eliminación y prevención de barreras burocráticas del INDECOPI. Así, se ha dispuesto, entre otros, que las resoluciones que declaran la existencia de una barrera burocrática ilegal tienen efectos

(29) Artículo 7. Documento Nacional de Identidad

El vencimiento de la fecha de vigencia del Documento Nacional de Identidad no constituye impedimento para la participación del ciudadano en actos civiles, comerciales, administrativos, notariales, registrales, judiciales, policiales y, en general, para todos aquellos casos en que deba ser presentado para acreditar su identidad.

(30) Artículo 37. Vigencia e invalidez del Documento Nacional de Identidad (DNI), obligación de actualizar datos y verificación de la dirección domiciliaria

37.1 El Documento Nacional de Identidad (DNI) tendrá una validez de ocho (8) años, vencido el cual será renovado por igual plazo.

(...) 
Milagros Maraví

generales, de manera que todos los administrados sean beneficiados y no se encuentren ante la obligación de iniciar un procedimiento de eliminación de barreras burocráticas. También se encuentra el requerimiento de doble filtro a efectos de que las entidades del Poder Ejecutivo puedan cuestionar las resoluciones del INDECOPI en sede judicial; así, necesitarán de la autorización de su máxima autoridad y la aprobación de la PCM. Igualmente, lo mencionado anteriormente es complementado con las actividades de prevención del INDECOPI, con la finalidad de concientizar a las propias entidades sobre la existencia y eliminación de las barreras burocráticas antes del inicio de un procedimiento de eliminación de barreras burocráticas.

Sin perjuicio de lo mencionado anteriormente, durante el periodo de delegación de facultades, se ha podido evidenciar que se emitieron diversos decretos legislativos que podrían ser cuestionables en su cumplimiento con la simplificación administrativa o la nueva normativa de la LPAG. Consideramos que si bien se pretende inaplicar la LPAG al Código Tributario por medio del Decreto Legislativo 1311, el mencionado código debería respetar los derechos y las garantías mínimos de los administrados en un procedimiento administrativo tributario. Igualmente, las entidades deberían realizar un análisis concienzudo sobre la aplicación de la responsabilidad subjetiva u objetiva en el procedimiento administrativo sancionador de su competencia, de modo que únicamente podría disponerse la responsabilidad objetiva cuando existan razones suficientes. Por su lado, el Decreto Legislativo 1246 necesita modificaciones menores a fin de que no se requiera la presentación de copias de partida de nacimiento o certificado de defunción una vez que se implemente la interoperabilidad; y se actualice el DNI cada cierto tiempo en razón a que la imagen e información de persona cambia con el paso del tiempo.

No tenemos menor duda de que la normativa expuesta es perfectible; sin embargo, se ha avanzado en nuestro ordenamiento del Derecho Administrativo a fin de ser un país propio de la OCDE.

\section{Referencias bibliográficas}

Baca Oneto, Víctor Sebastián. 2011. La prescripción de las infracciones y su clasificación en la Ley del Procedimiento Administrativo General (En especial, análisis de los supuestos de infracciones permanentes y continuadas). Revista Derecho \& Sociedad 37: 263- 74.

Caballero Sánchez, Rafael. 1999. Prescripción y caducidad en el ordenamiento administrativo. España: McGraw Hill.

Huapaya Tapia, Ramón. 2013. Administración Pública, Derecho Administrativo y Regulación. Estudios y Cuestiones. Lima: Ara Editores.

Maraví Sumar, Milagros. 2000. La simplificación administrativa: un asunto completo. THEMIS 40: 289-99.

2011. Avances a los diez años de vigencia de la Ley del Procedimiento Administrativo General. Derecho PUCP 67: 109-23.

Martínez Gutiérrez, Rubén. 2010. El Procedimiento Administrativo electrónico en los ordenamientos Peruano y Español. Círculo de Derecho Administrativo 9: 95-113.

Martínez Zamora, Marco Antonio. 2015. La Responsabilidad Objetiva de los Proveedores del Estado en la Presentación de Documentación Falsa o Declaración Jurada Inexacta. Derecho \& Sociedad 44: 121-38.

Morón Urbina, Juan Carlos. 2005. Los principios delimitadores de la potestad sancionadora de la administración pública en la ley peruana. Advocatus 13: 237-58.

2011. La revocación de actos administrativos, interés público y seguridad jurídica. Derecho PUCP 67: 419 - 55.

2014. Comentarios a la Ley del Procedimiento Administrativo General. Lima: Gaceta Jurídica.

Ochoa, Francisco. 2014. Fundamentos del procedimiento de eliminación de barreras 
Mecanismos de simplificación administrativa a la luz de las recientes modificaciones a la Ley del Procedimiento Administrativo General, Ley 27444, y la reciente Ley de Prevención y Eliminación de Barreras Burocráticas, Decreto Legislativo 1256

Mechanisms for administrative simplification in light of recent amendments to the General Administrative Procedure Law, 27444, and the recent Law of Prevention and Elimination of Bureaucratic Barriers, Legislative Decree 1256

burocráticas. Revista INDECOPI 19: 1-56. http://revistas.indecopi.gob.pe/index.php/rcpi/ article/viewFile/134/129 (consultada el 10 de marzo de 2017).

2016. ¿Es posible hacer cumplir la ley sin sancionar? Aplicando de manera "responsiva" la regulación en el Perú, a propósito del caso de abogacía de la competencia sobre las barreras burocráticas en el mercado de servicios públicos. Derecho PUCP 76: 151-180. https://doi.org/10.18800/ derechopucp.201601.006

Organización para la Cooperación y el Desarrollo Económicos. 2009. Overcoming Barriers to Administrative Simplification
Strategies. Guidance for Policy Makers: París: OCDE. http:// www.oecd.org/regreform/42112628.pdf (consultada el 3 de marzo de 2017).

2016. Política Regulatoria en el Perú. Uniendo el marco para la calidad regulatoria. París: OCDE. http://www. oecd.org/gov/regulatory-policy/Poli \%CC\%81tica-Regulatoriaen-el-Peru\%CC\%81-aspectos-clave.pdf (consultada el 10 de marzo de 2017).

Sagüés, Néstor Pedro. 1997. Jurisdicción constitucional y seguridad jurídica. Pensamiento Constitucional 4: 217-32.

Siegan, Bernand. 1993. Reforma Constitucional. Perú: Citel.

Zanobini, Guido. 1954. Curso de Derecho Administrativo. Argentina: Ediciones Arayu.

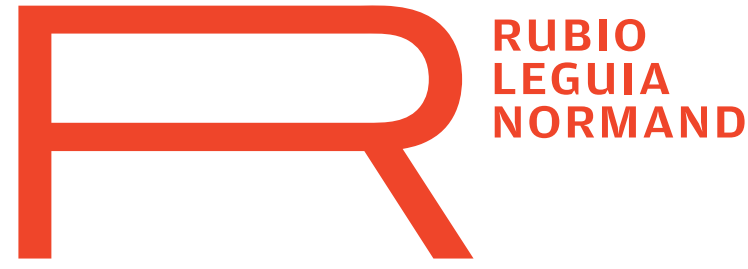

